\title{
Tumor development in murine ulcerative colitis depends on MyD88 signaling of colonic $\mathrm{F} 4 / 80^{+} \mathrm{CD} 11 \mathrm{~b}^{\text {high }} \mathrm{Gr} 1^{\text {low }}$ macrophages
}

\author{
Gabriela Schiechl, ${ }^{1}$ Bernhard Bauer, ${ }^{1}$ Ivan Fuss, ${ }^{2}$ Sven A. Lang, ${ }^{1}$ Christian Moser, ${ }^{1}$ \\ Petra Ruemmele, ${ }^{3}$ Stefan Rose-John, ${ }^{4}$ Markus F. Neurath, ${ }^{5}$ Edward K. Geissler, ${ }^{1}$ \\ Hans-Jürgen Schlitt, ${ }^{1}$ Warren Strober, ${ }^{2}$ and Stefan Fichtner-Feigl' \\ ${ }^{1}$ Department of Surgery, University of Regensburg, Regensburg, Germany. ${ }^{2}$ Mucosal Immunity Section, \\ Laboratory of Host Defenses, National Institute of Allergy and Infectious Diseases, NIH, Bethesda, Maryland, USA. \\ ${ }^{3}$ Department of Pathology, University of Regensburg, Regensburg, Germany. ${ }^{4}$ Institute of Biochemistry, University of Kiel, \\ Kiel, Germany. ${ }^{5}$ Department of Medicine 1, University Hospital Erlangen, Erlangen, Germany.
}

\begin{abstract}
Patients with prolonged ulcerative colitis (UC) frequently develop colorectal adenocarcinoma for reasons that are not fully clear. To analyze inflammation-associated colonic tumorigenesis, we developed a chronic form of oxazolone-induced colitis in mice that, similar to UC, was distinguished by the presence of IL-13-producing NKT cells. In this model, the induction of tumors using azoxymethane was accompanied by the coappearance of $\mathrm{F} 4 / \mathbf{8 0}^{+} \mathrm{CD} 11 \mathrm{~b}^{\text {high }} \mathrm{Gr} 1^{\text {low }} \mathrm{M} 2$ macrophages, cells that undergo polarization by IL-13 and are absent in tumors that lack high level IL-13 production. Importantly, this subset of macrophages was a source of tumor-promoting factors, including IL-6. Similar to dextran sodium sulfate-induced colitis, $\mathrm{F} 4 / 80^{+} \mathrm{CD} 11 \mathrm{~b}^{\text {high }} \mathrm{Gr} \mathbf{1}^{\text {intermediate }}$ macrophages were present in the mouse model of chronic oxazolone-induced colitis and may influence tumor development through production of TGF- $\beta 1$, a cytokine that inhibits tumor immunosurveillance. Finally, while robust chronic oxazolone-induced colitis developed in myeloid differentiation primary response gene 88-deficient $\left(M y d 88^{-/-}\right)$mice, these mice did not support tumor development. The inhibition of tumor development in $M y d 88^{-/-}$ mice correlated with cessation of IL- 6 and TGF- $\beta 1$ production by $\mathrm{M} 2$ and $\mathrm{F} 4 / 80^{+} \mathrm{CD} 11 \mathrm{~b}^{\text {high }} \mathrm{Gr} \mathbf{1}^{\text {intermediate }}$ macrophages, respectively, and was reversed by exogenous IL-6. These data show that an UC-like inflammation may facilitate tumor development by providing a milieu favoring development of MyD88-dependent tumorsupporting macrophages.
\end{abstract}

\section{Introduction}

Ulcerative colitis (UC), 1 of the 2 major forms of human inflammatory bowel disease, is marked by superficial ulcerative inflammation limited to the large bowel $(1,2)$. Recent work has shown that it is characterized immunologically by the presence of NKT cells that produce IL-13 $(3,4)$. Thus, the ulceration and inflammation may be due to injury of epithelial cells caused by IL-13-facilitated NKT cell cytotoxic activity and/or direct effects of IL-13 (5).

Patients with prolonged UC are subject to the frequent development of colorectal adenocarcinoma (6-8). The reasons for this increased cancer occurrence are not fully understood, but there is ample evidence from murine models that the presence of chronic inflammation provides an environment that favors the growth of neoplastic cells (9-13). Thus, in recent studies of a murine model of colitis, dextran sodium sulfate-induced colitis (DSS-colitis), it was shown that the inflammation is a necessary antecedent for the induction of colon tumors by a carcinogenic agent, azoxymethane (AOM) (13-17). In addition, it was shown that such inflammation supports the development of colon tumors via the production of the cytokine IL-6 $(14,18,19)$.

While studies of the effect of an inflammatory milieu on tumor formation using DSS-colitis have been quite useful, their application to the study of tumor formation in UC is limited by the fact that this model bears little immunologic similarity to UC. A

Conflict of interest: The authors have declared that no conflict of interest exists. Citation for this article: J Clin Invest. 2011;121(5):1692-1708. doi:10.1172/JCI42540. more relevant model would be oxazolone-induced colitis (oxacolitis), since this haptene-induced colitis bears some histologic resemblance to UC and, like the human disease, is associated with the presence of NKT cells that produce IL-13 (3, 20, 21). However, the oxa-colitis studied so far is ill adapted to investigate tumorigenesis, because the latter is an acute inflammation, and tumor development requires time to evolve. To overcome this problem, we developed a chronic model of oxa-colitis in BALB/c mice, induced by repeated rectal administration of low doses of oxazolone. As shown in the studies described here, the mice subjected to this regimen developed a chronic inflammation that, like UC, is associated with the development of NKT cells and increased IL-13 production and is, in fact, dependent on these factors.

With this model in hand, we conducted studies of the cells in the inflammatory infiltrate accompanying the development of AOMinduced colonic tumors. A major finding was that the appearance of tumors approximately 4-5 weeks after AOM administration (at the time of initial oxazolone treatment) was accompanied by the coappearance of a F4/80 $\mathrm{CD} 11 \mathrm{~b}^{\text {high }} \mathrm{Gr} 1^{\text {low }}(\mathrm{M} 2)$ macrophage subset. Previous studies have shown that such cells arise from "alternative activation" under the influence of Th2 cytokines, and it thus seems likely that they had undergone such activation in the inflamed lamina propria of mice with oxa-colitis as a result of exposure to IL-13 produced by NKT cells (22-27). This possibility finds support in the fact that these macrophages are not found in mice with DSS-colitis and AOM-induced tumors that lack IL-13 production. In studies assessing the role of these cells 
in tumor formation, we found that they were a major source of tumor-supporting factors, such as IL-6 and EGF. In addition, we showed that in myeloid differentiation primary response gene 88 deficient ( $\left.M y d 88^{--}\right)$mice with oxa-colitis that displayed severely curtailed AOM-tumor formation, these cells produced greatly reduced levels of the above tumor-supporting factors. Finally, tumor-supporting factors in BM chimeras with oxa-colitis was greatly reduced following reconstitution with $M y d 88^{-1-}$ hematopoietic cells. Overall, these studies suggest that tumor development in the Th2-like oxa-colitis resembling human UC depends on a macrophage subset that secrets tumor-supporting factors as a result of MyD88 signaling.

\section{Results}

Clinical features of chronic oxa-colitis in $B A L B / c$ mice. In initial studies, we established a chronic form of oxa-colitis suitable for the study of a NKT cell-mediated chronic inflammation mimicking UC and the development of colon tumors. We used an approach taken previously to develop a chronic form of TNBS-colitis (20, 28-30), namely the administration of low intrarectal doses of an inducing agent (in this case oxazolone rather than TNBS) in ethanol to $\mathrm{BALB} / \mathrm{c}$ mice every 7 days for the duration of the study (10 weeks). As shown in Figure 1A, during the first 3 weeks of this treatment, the mice lost about $10 \%-15 \%$ of their starting weight and exhibited ruffled coats, hunched posture, and restricted movement. During this period $10 \%-15 \%$ of animals died. Over the next 3 weeks the surviving mice regained weight and no longer exhibited obvious signs of chronic illness; however, in the ensuing and final 4 weeks of observation, while the oxazolone-treated mice maintained their starting weight, littermate control mice continued to gain weight. Repetitive administration of intrarectal ethanol alone led to a weight loss of up to $5 \%$ in the early phase of the disease. However, after this period the mice gained weight almost to the same extent as their littermate controls.

The above "clinical" response to intrarectal oxazolone administration correlated with histology. Thus, as shown in Figure 1B, during the first 1 to 2 weeks of disease the colon was characterized by infiltration of inflammatory cells (including lymphocytes, macrophages, and neutrophils) and epithelial cell disruption similar to that seen in the acute form of oxa-colitis and ranging in size from microulcerations of 5 to 20 epithelial cells in diameter to macroulcerations of 1 to $2 \mathrm{~mm}$ in diameter $(20,21,31,32)$. Then, during the 4 th through 7 th weeks, the level of inflammatory cell infiltration as well as areas with epithelial ulceration declined somewhat and then remained stable until the end of the observation period at 10 weeks.

Chronic oxa-colitis with AOM-induced tumor formation. In previous studies, inflammation-associated colonic tumors were noted in mice with DSS-colitis administered AOM. To determine whether oxa-colitis would support AOM-induced tumor development, we administered a single i.p. injection of AOM to mice at the same time as the first dose of oxazolone to initiate chronic oxa-colitis. Whereas mice not administered AOM never developed tumors, a single dose of AOM led to colonic tumor formation in the distal half of the colon. Tumor nodules were initially noted 4-5 weeks after colitis initiation, indicating that tumor growth depended on the presence of an inflammatory milieu. However, as shown in Figure 1A, the course of disease was different in mice that developed tumors: mice with oxa-colitis and AOM-induced tumors exhibited a more severe weight loss, beginning on day 21 , which was only partially regained and was followed at 8 to 9 weeks by a significant drop in body weight. The onset of this second weight loss coincided with the time of development of tumor obstruction of the colon and led to death in $15 \%$ of the animals.

These differences in clinical course were reflected in histologic studies of tissue. Thus, as shown in Figure 1, B and C, whereas the inflammation in mice with oxa-colitis with tumor development was not appreciably different from that in mice with oxa-colitis without tumor development, increasing numbers of tumor nodules were detected in the colons of the former group of mice over the initial 7 weeks of disease. In addition, while the number of nodules tended to level off after this period, individual nodules continued to increase in size. The average tumor diameter at day 35 was $2.6 \pm 1.1 \mathrm{~mm}$ (25 tumors evaluated), and at day 70 it increased to $4.1 \pm 1.1 \mathrm{~mm}$ (25 tumors evaluated). It should be noted that the tumor nodules were comprised of neoplastic epithelial cells not found in mice with chronic oxa-colitis without tumors. This is illustrated in Figure 1D, which shows that the tumor epithelial cells displayed increased expression and abnormal distribution of $\beta$-catenin: whereas low levels of membrane-associated $\beta$-catenin were found in normal epithelial cells, high amounts of this component were found in tumor epithelial cells, both membrane-associated as well as in the cytoplasm. This change reflects an activation of the $\beta$-catenin pathway that is characteristic of both AOM tumors and human colon adenocarcinomas $(15,33)$. As shown in Figure 1E, tumor formations in chronic oxa-colitis were represented by flat, tubular, villous, or tubulovillous adenomas; the flat adenomas contained cells exhibiting mostly low-grade intraepithelial neoplasia (IEN), whereas the other types contained cells exhibiting a more equal distribution of low-grade to high-grade IEN. In addition, when tumor nodules were subjected to observation for longer than 10 weeks after AOM administration, rare foci of invasive carcinoma were noted.

Cytokine expression during the course of oxa-colitis, with and without AOM-induced tumors. In further studies, we determined the cytokine profile of lamina propria mononuclear cells (LPMCs) during chronic oxa-colitis with and without AOM-induced tumors by stimulating extracted LPMCs ex vivo with anti-CD3/CD28 antibody for evaluation of IL-13, IFN- $\gamma$, and IL-17 or with Staphylococcus aureus Cowan I plus IFN- $\gamma$ for evaluation of TNF- $\alpha$ and IL- 6 (see Methods). As shown in Figure 2A, we noted that LPMCs produced increasing amounts of IL-13 during the first 21 days of chronic oxa-colitis, which then was maintained at a high plateau for the duration of the colitis. LPMCs from mice with AOM-induced tumors displayed an identical IL-13 secretion pattern. However, as shown in Supplemental Figure 1 (supplemental material available online with this article; doi:10.1172/JCI42540DS1), LPMC secretion of IFN- $\gamma$ declined after the first week of chronic oxa-colitis to levels below those in naive mice, whereas secretion of IL-17 rose steadily until reaching a plateau at about 56 days. LPMC secretion of TNF- $\alpha$ showed a peak during the initial 2 weeks of the colitis and remained slightly increased (compared with baseline) during the chronic phase of oxa-colitis. Importantly, this pattern of IFN- $\gamma$, IL-17A, and TNF- $\alpha$ secretion was also seen in LPMCs from mice with AOM-induced tumors. Finally, as shown in Supplemental Figure 1, chronic oxa-colitis was associated with increased IL-33 expression, which peaked between days 7 and 28 .

A different pattern emerged with respect to IL-6. Thus, as shown in Figure 2A, LPMCs from mice with oxa-colitis without AOM-induced tumors displayed only a modest increase in IL-6 secretion in the first week of colitis, which then persisted at this 
A
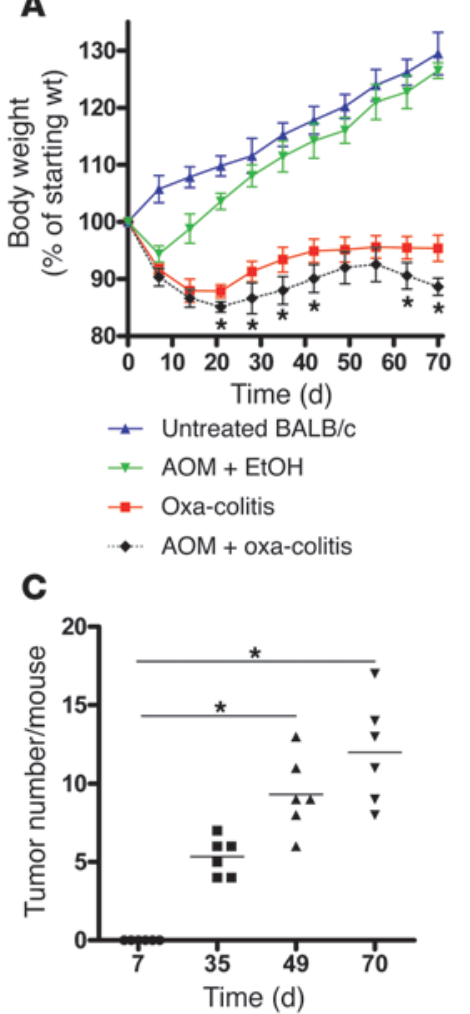

B
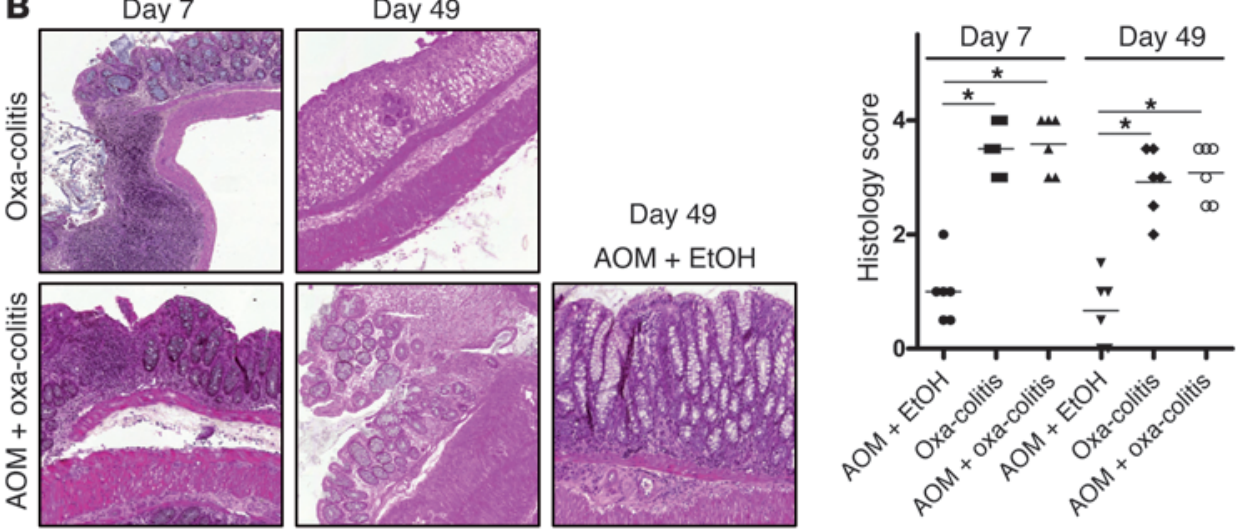

D

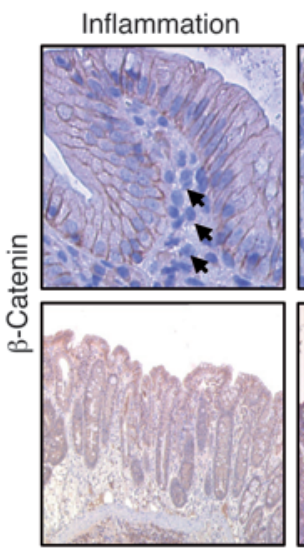

\begin{abstract}
Colon tumor
\end{abstract}
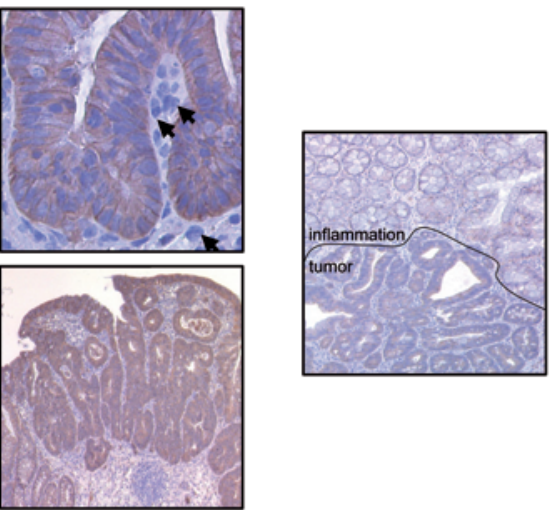

E

Flat adenoma

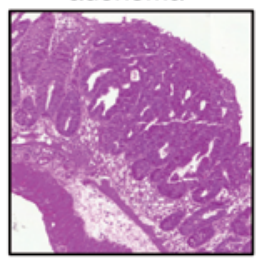

Tubular adenoma

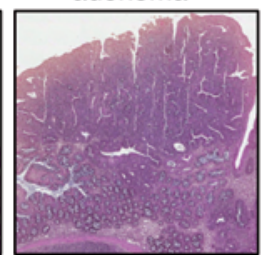

Villous
adenom

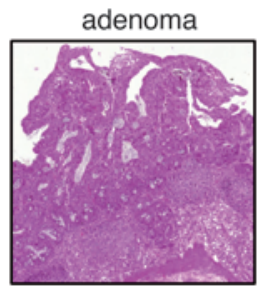

Tubulovillous adenoma

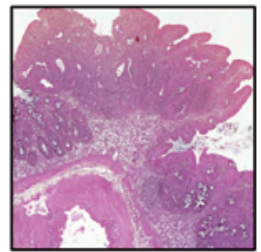

Invasive carcinoma

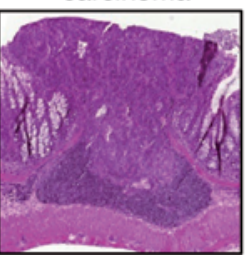

Figure 1

Features of mice with chronic oxa-colitis. (A) Body weight as a percentage of starting weight. Data shown are mean \pm SEM $(n=6$ mice per group). ${ }^{*} P \leq 0.05$ tested for oxa-colitis group and AOM plus oxa-colitis group. (B) H\&E staining of representative inflamed areas of colon sections and histology score on day 7 and day 49 of oxa-colitis (original magnification, $\times 10$ ). Horizontal bars are mean values ( $n=6$ mice per group). Each individual symbol represents 1 mouse. ${ }^{*} P \leq 0.05$. (C) Number of tumor nodules during oxa-colitis with AOM-induced tumors. Horizontal bars are mean values ( $n=6$ mice per group). Individual symbols represent 1 mouse. ${ }^{*} P \leq 0.05$. (D) Immunohistochemistry staining for $\beta$-catenin of representative inflamed areas and tumor areas of colon sections on day 49 during oxa-colitis and oxa-colitis with AOM-induced tumors (original magnification, $\times 40$ [top 2 panels]; $\times 10$ [bottom 2 panels]; $\times 7.5$ [right single panel]). Arrows indicate exemplary inflammatory cells. (E) H\&E staining of representative colon tumors of oxa-colitis (original magnification, $\times 7.5$ ).

level. In contrast, while LPMCs from mice with oxa-colitis with tumors exhibited only a slight increase in IL-6 secretion in the first 2 weeks of colitis, after that time, it increased progressively to plateau at 5 weeks at a level at least 3-fold higher than the plateau of mice without tumors.

In further studies, to determine whether AOM-induced tumors were not only associated with increased IL- 6 production but also dependent on such production, we determined the effect of IL- 6 blockade by anti-IL- 6 antibody administration on oxa-colitis inflammation and on tumor development. As shown in Figure 2B, administration of either anti-IL-6 antibody or control IgG $(0.5 \mathrm{mg}$ i.p. each week, starting on day 20) had no effect on the initial body weight loss, but anti-IL-6 antibody did attenuate the second phase of weight loss (which is likely due to mechanical ileus caused by intraluminal tumor). As shown in Figure 2, C and D, these weight changes correlated with histology in that blockade of IL-6 did not lead to reduced inflammation or IL-13 production. Nonetheless, as shown in Figure 2E, inhibition of IL-6 led to a profound reduction in tumor formation and thus explained the ability of IL- 6 blockade to abolish the second phase of weight loss. Furthermore, the intracellular expression pattern of $\beta$-catenin was not changed by the inhibition of IL-6, indicating that the latter cytokine does not 
A

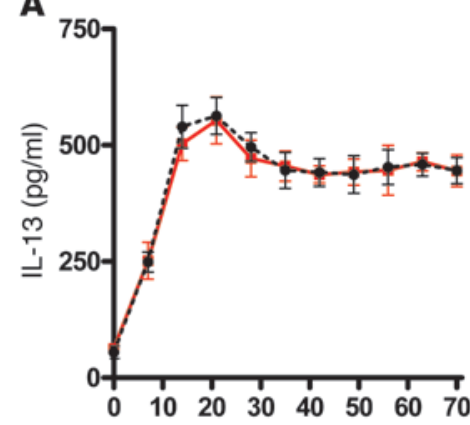

Days after oxa initiation

-. Oxa-colitis

$\because \mathrm{AOM}+$ oxa-colitis

B

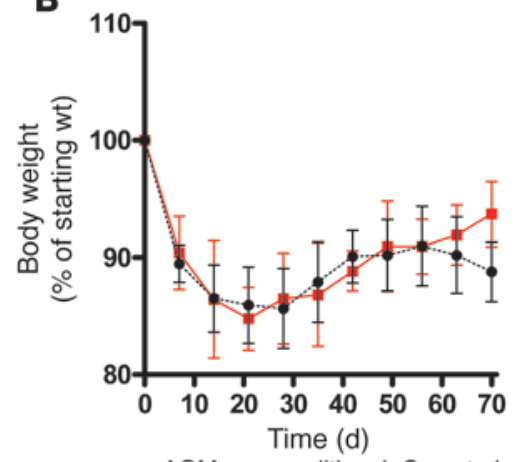

-.. $\mathrm{AOM}+$ oxa-colitis + IgG control

$=\mathrm{AOM}+$ oxa-colitis + anti-IL-6

D

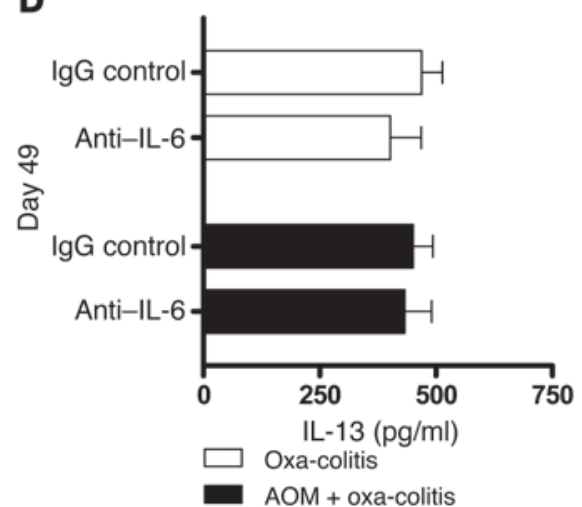

C

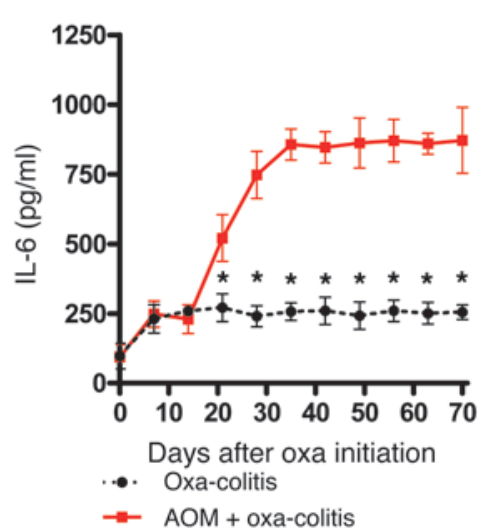

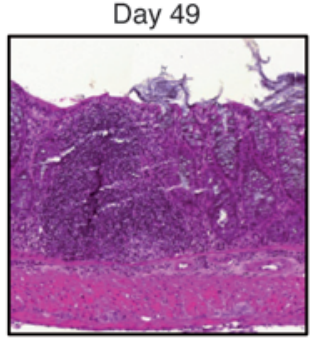

$\mathrm{AOM}+$ oxa-colitis + anti-IL-6

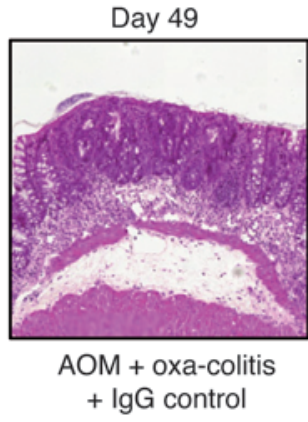

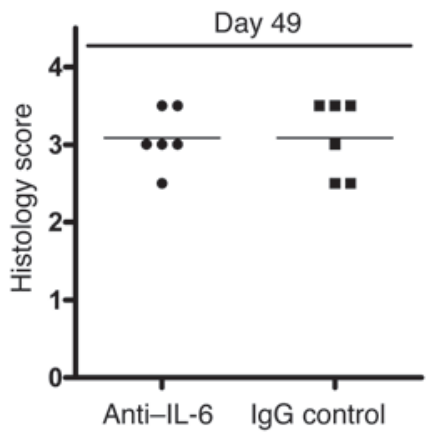

E

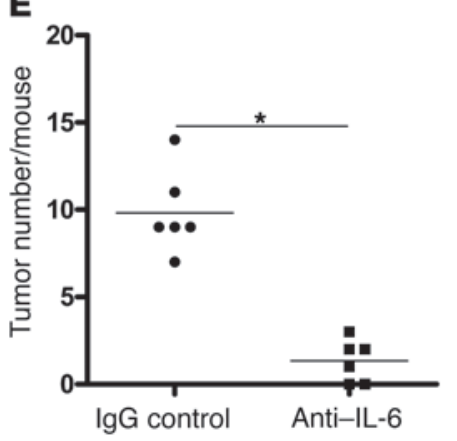

\section{Figure 2}

Cytokine expression and IL-6 dependency of AOM-induced tumors. (A) Cytokine expression during chronic oxa-colitis and chronic oxa-colitis with AOM-induced tumors. Cells were extracted from the lamina propria and stimulated for 48 hours. Cytokine concentrations were determined in culture supernatants by ELISA. Data shown are mean \pm SEM from individual cultures of cells derived from mice in 2 separate experiments ( $n=6$ mice per group). ${ }^{*} P \leq 0.05$. (B) Body weight after treatment with anti-IL-6 antibody. Data shown are mean \pm SEM ( $n=6$ mice per group). (C) H\&E staining of representative inflamed areas of colon sections (original magnification, $\times 10$ ) and histology score on day 49 of oxa-colitis with AOM-induced tumors following treatment with anti-IL-6 antibody. Horizontal bars are mean values ( $n=6$ mice per group). Individual symbols represent 1 mouse. (D) IL-13 production on day 49 of oxa-colitis and oxa-colitis with AOM-induced tumors after treatment with anti-IL-6 antibody. Cells were extracted from the lamina propria on day 49. Cytokine concentrations were determined in culture supernatants by ELISA. Data shown are mean \pm SEM from individual cultures of cells derived from mice in 2 separate experiments $\left(n=6\right.$ mice per group). ${ }^{*} P \leq 0.05$. (E) Number of tumor nodules on day 49 of oxa-colitis with AOM-induced tumors after treatment with anti-IL-6 antibody. Horizontal bars are mean values $(n=6$ mice per group). Individual symbols represent 1 mouse. ${ }^{*} P \leq 0.05$.

influence early neoplastic changes in epithelial cells induced by AOM (Supplemental Figure 2). Overall, these findings established that support of tumor formation in WT mice requires inflammation accompanied by production of IL- 6 .
NKT cells producing IL-13 drive chronic oxa-colitis. Previous work has shown that NKT cells that produce IL-13 play an essential role in the pathogenesis of acute oxa-colitis (21). To establish the role of these cells in chronic oxa-colitis, we first enumerated these cells 
A
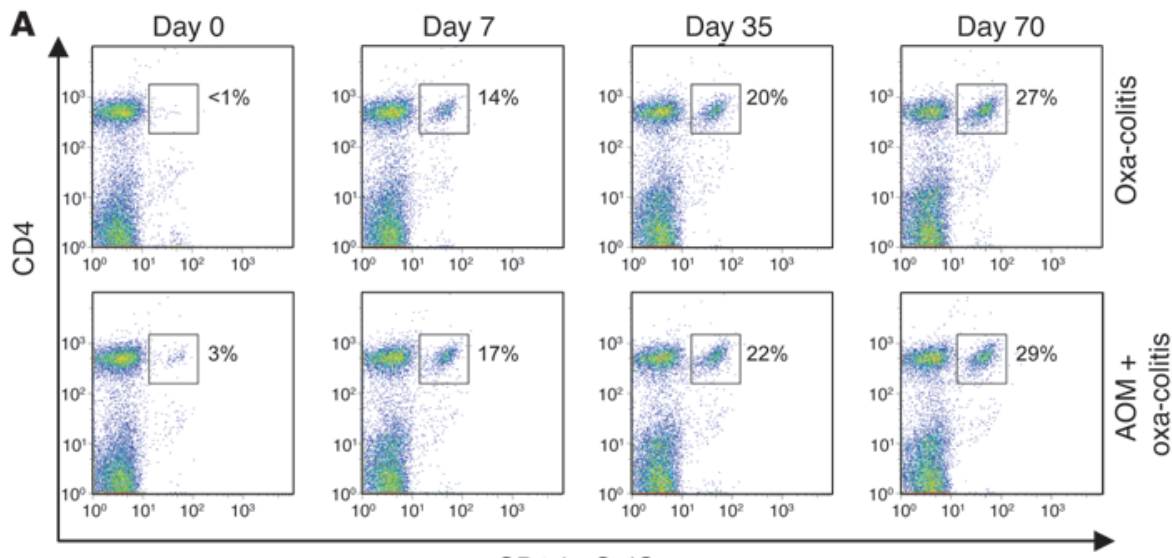

CD1d $\alpha$ GalCer

B

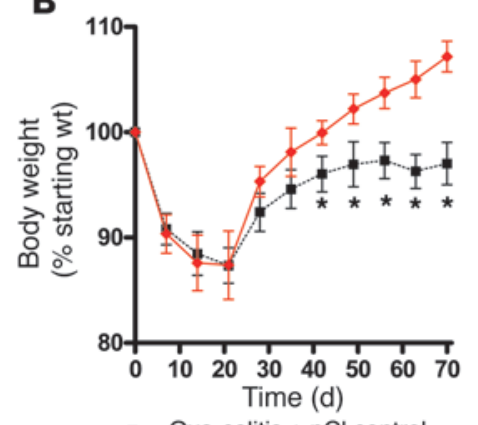

-.. Oxa-colitis $+\mathrm{pCl}$ control

$\rightarrow$ Oxa-colitis + pCl-sIL-13R $\alpha_{2}-\mathrm{Fc}$

\section{D}

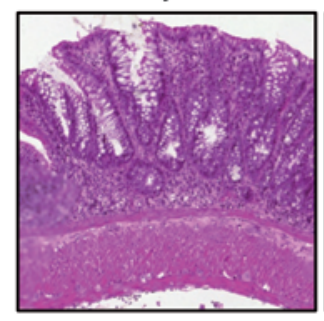

Oxa-colitis + pCl-sIL-13R $\alpha_{2}-F c$

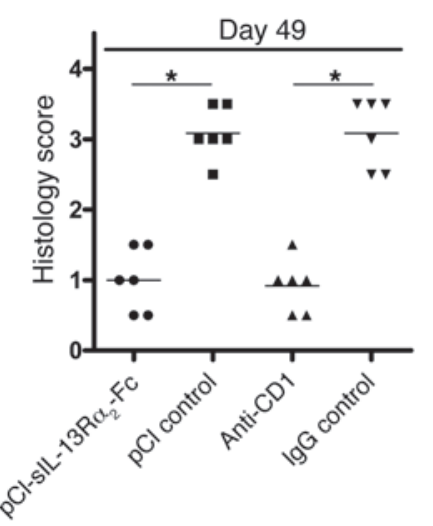

Day 49

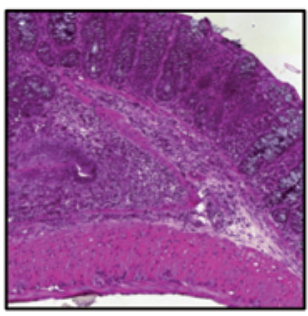

Oxa-colitis + $\mathrm{pCl}$ control

E
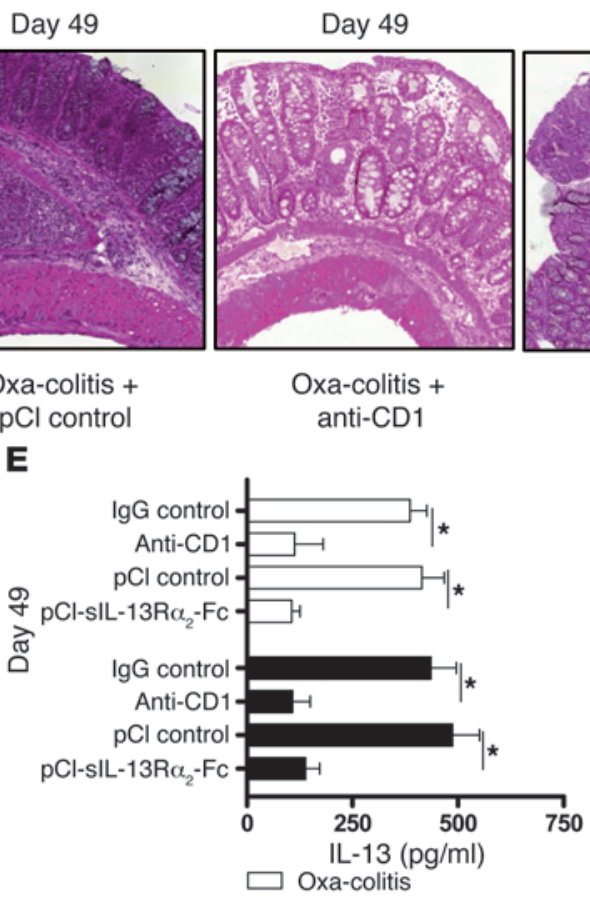

Oxa-colitis + anti-CD1
C

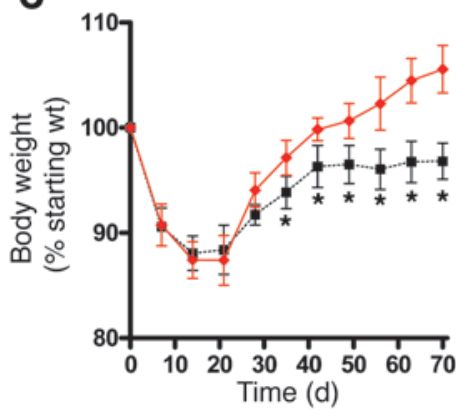

-.. Oxa-colitis + IgG control

$\rightarrow$ Oxa-colitis + anti-CD1

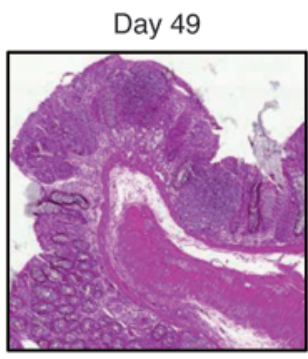

Oxa-colitis + IgG control

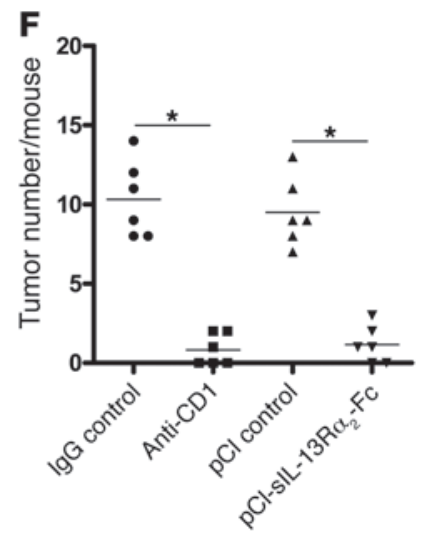




\section{Figure 3}

Role of NKT cells during chronic oxa-colitis. (A) NKT cell expression during oxa-colitis and oxa-colitis with AOM-induced tumors. Cells were extracted from the lamina propria and stained with anti-CD4 antibody and CD1d $\alpha$ GalCer tetramers. Percentages denote the percentages of $\mathrm{CD} 4{ }^{+} \mathrm{CD} 1 \mathrm{~d} \alpha \mathrm{GalCer}{ }^{+}$cells among total $\mathrm{CD} 4{ }^{+}$cells. (B) Body weight after treatment with $\mathrm{pCl}-\mathrm{sIL}-13 \mathrm{R} \alpha_{2}-\mathrm{Fc}$. Data shown are mean \pm SEM ( $n=6$ mice per group). ${ }^{*} P \leq 0.05$ tested for $\mathrm{pCl}$ control group and $\mathrm{pCl}-\mathrm{sIL}-13 \mathrm{R} \alpha_{2}-\mathrm{Fc}$ group. (C) Body weight after treatment with anti-CD1 antibody. Data shown are mean \pm SEM ( $n=6$ mice per group). ${ }^{*} P \leq 0.05$ tested for IgG control group and anti-CD1 group. (D) H\&E staining of representative colon sections (original magnification, $\times 10$ ) and histology score on day 49 during oxa-colitis after treatment with $\mathrm{pCl}-\mathrm{sIL}-13 \mathrm{R} \alpha_{2}-\mathrm{Fc}$ or anti-CD1 antibody. Horizontal bars are mean values ( $n=6$ mice per group). Individual symbols represent 1 mouse. ${ }^{*} P \leq 0.05$. (E) IL-13 production on day 49 of oxa-colitis and oxa-colitis with AOM-induced tumors after treatment with $\mathrm{pCl}-\mathrm{slL}-13 \mathrm{R} \alpha_{2}-\mathrm{Fc}$ or anti-CD1 antibody. Cells were extracted from the lamina propria on day 49 . Cytokine concentrations were determined in culture supernatants by ELISA. Data shown are mean \pm SEM from individual cultures of cells derived from mice in 2 separate experiments ( $n=6$ mice per group). ${ }^{*} P \leq 0.05$. (F) Number of tumor nodules on day 49 of oxa-colitis with AOM-induced tumors after treatment with $\mathrm{pCl}-\mathrm{sIL}-13 \mathrm{R} \alpha_{2}-\mathrm{Fc}$ or anti-CD1 antibody. Horizontal bars are mean values ( $n=6$ mice per group). Individual symbols represent 1 mouse. ${ }^{*} P \leq 0.05$.

by staining isolated LPMCs with fluorescent anti-CD4 antibody and CD1d $\alpha$ GalCer tetramer. As shown in Figure 3A, on day 7 of colitis, approximately $15 \%$ of CD $4^{+} \mathrm{T}$ cells were NKT cells, and this percentage steadily increased, so that on day $70,25 \%-30 \%$ of $\mathrm{CD}^{+}$ cells were NKT cells.

We next determined whether IL-13 blockade or depletion of NKT cells affected chronic oxa-colitis or AOM-induced tumor development. To achieve IL-13 blockade, we administered a plasmid-encoding soluble IL-13 receptor- $\alpha 2-\mathrm{Fc}$ fusion protein (pCI-sIL-13R $\alpha_{2}-\mathrm{Fc}$ ) or a control plasmid (pCI empty vector) by intranasal instillation every other day, starting on day 20 after initiation of chronic oxa-colitis $(28,29)$. We verified that such intranasal administration of the $s I L-13 R \alpha_{2}-F c$ plasmid results in expression of sIL-13R $\alpha_{2}-\mathrm{Fc}$ in colonic tissue by demonstrating that human Ig-Fc (a component of the plasmid product) is expressed in colonic tissue extracts after administration of the plasmid (data not shown). As shown in Figure 3B, blockade of IL-13 starting on day 20 of chronic oxa-colitis without AOM-induced tumors resulted in an increase in body weight in contrast to that of mice treated with control plasmid. As shown in Supplemental Figure 3A, a similar effect of intranasal $s I L-13 R \alpha_{2}-F c$ plasmid administration was seen in mice with chronic oxa-colitis and AOM-induced tumors. In this case, treatment reversed both the initial weight loss as well as the secondary weight loss seen in control-treated mice.

To achieve NKT cell depletion, we administered anti-CD1 antibody ( $0.5 \mathrm{mg}$ i.p. each week, starting on day 20) to mice with chronic oxa-colitis. As shown in Figure 3C and Supplemental Figure $3 \mathrm{~B}$, such treatment also resulted in weight gain in both mice with chronic oxa-colitis and in mice with chronic oxa-colitis with tumors. As shown in Supplemental Figure 4, the administration of anti-CD1 antibody led to an approximately $90 \%$ decrease in the number of $\mathrm{CD}^{+} \alpha \mathrm{GalCer}$-tetramer ${ }^{+} \mathrm{NKT}$ cells in the lamina propria as well as in the circulation but had no measurable effect on the total number of $\mathrm{CD}^{+} \mathrm{T}$ cells in these sites.
The effects of blockade of IL-13 and depletion of NKT cells were also manifest in histologic studies of both mice with oxacolitis without and with AOM-induced tumors. Thus, as shown in Figure 3D, whereas characteristic signs of inflammation (i.e., infiltration of inflammatory cells, epithelial cell disruption, and edematous swelling of the colon wall) were visible in histologic sections obtained on day 49 in mice administered control plasmid or control IgG starting on day 20, only slight inflammatory changes were noted in mice administered the $s I L-13 R \alpha_{2}-F c$ plasmid or antiCD1 antibody. Therefore, inhibition of either IL-13 or NKT cells resulted in a reversal of the inflammation in both mouse groups.

Finally, as shown in Figure 3E, treatment with either $s I L-13 R \alpha_{2}-F c$ plasmid or anti-CD1 antibody reduced LPMC IL-13 production in both groups of mice. Since depletion of NKT cells led to decreased IL-13, these data confirm previous studies showing that IL-13 is being produced by NKT cells $(3,21)$.

Reversal of oxa-colitis aborts tumor development in AOM-treated mice. As could be predicted from weight changes of mice with chronic oxa-colitis administered AOM, this treatment had an effect on tumor development. Thus, mice subjected to blockade of IL-13 or depletion of NKT cells showed greatly reduced numbers of tumor nodules on day 49 compared with animals receiving control reagents (Figure 3F). In addition, the size of each nodule was reduced. On day 49, the average tumor diameter of mice treated with IgG control was $3.5 \pm 0.9 \mathrm{~mm}$ (25 tumors evaluated), that of mice treated with anti-CD1 antibody was $1.4 \pm 0.5 \mathrm{~mm}$ (10 tumors evaluated), that of mice treated with pCI control plasmid was $3.7 \pm 0.9 \mathrm{~mm}$ (25 tumors evaluated), and that of mice treated with pCI-sIL-13R $\alpha_{2}-F c$ was $1.6 \pm 0.6 \mathrm{~mm}$ (10 tumors evaluated).

Tumor formation is associated with the appearance of $\mathrm{F} 4 / 80^{+} \mathrm{CD} 11 \mathrm{~b}^{\text {high }} \mathrm{Gr} 1^{\text {low }}$ macrophages producing tumor-supporting factors. The dependence of tumor growth on the presence of inflammation suggested that the latter was characterized by the presence of cells that support tumor growth. Based on a previous report that a particular macrophage subset supports pulmonary metastases arising from mammary carcinomas, we examined macrophage phenotype and function in isolated LPMCs of tumor-bearing and non-tumor-bearing mice with colitis (24). As shown in Figure 4A, we found that the appearance of tumors in chronic oxa-colitis was closely accompanied by the coappearance of LPMCs containing a substantial subset of $\mathrm{F} 4 / 80^{+} \mathrm{CD} 11 \mathrm{~b}^{\text {high }} \mathrm{Gr} 1^{\text {low }}$

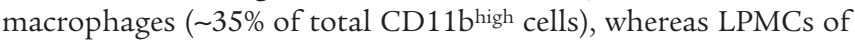
mice with chronic oxa-colitis not associated with tumor formation contained only a very low percentage of these cells $(1 \%-2 \%$ of total CD11bhigh cells). In contrast, LPMCs from normal mice as well as mice with chronic oxa-colitis with and without tumors contained similar numbers of $\mathrm{F} 4 / 80^{+} \mathrm{CD} 11 \mathrm{~b}^{\text {high }} \mathrm{Gr} 1^{\text {intermediate }}$ cells. Finally, LPMCs from mice with tumors contained a somewhat reduced number of $\mathrm{F} 4 / 80^{+} \mathrm{CD} 11 \mathrm{~b}^{\text {high }} \mathrm{Gr} 1^{\text {high }}$ cells (granulocytes).

We next assessed production of tumor-supporting factors, such as IL-6 and EGF, by macrophage subsets. To this end, we first obtained $\mathrm{F} 4 / 80^{+} \mathrm{CD} 11 \mathrm{~b}^{\text {high }} \mathrm{Gr} 1^{\text {low }}$ and $\mathrm{F} 4 / 80^{+} \mathrm{CD} 11 \mathrm{~b}^{\text {high }} \mathrm{Gr} 1^{\text {intermediate }}$ subpopulations from LPMCs by cell sorting and then determined Il6 and Eg $\mathrm{mRNA}$ production by these subpopulations using realtime PCR. As shown in Figure 4B, while F4/80+CD $11 b^{\text {high }} \mathrm{Gr} 1^{\text {low }}$ cells in LPMCs of mice with oxa-colitis without tumors produced slightly higher amounts of Il6 on day 35 and an equivalent amount of Egf mRNA compared with that of $\mathrm{F} 4 / 80^{+} \mathrm{CD} 11 \mathrm{~b}^{\text {high }} \mathrm{Gr} 1^{\text {intermediate }}$ cells, F4/80 $\mathrm{CD} 11 \mathrm{~b}^{\text {high }} \mathrm{Gr} 1^{\text {low }}$ cells in LPMCs of mice with colitis and tumors produced greatly increased amounts of both $\mathrm{Il} 6$ and Egf starting on day 35 as compared with that of their counterpart 
A
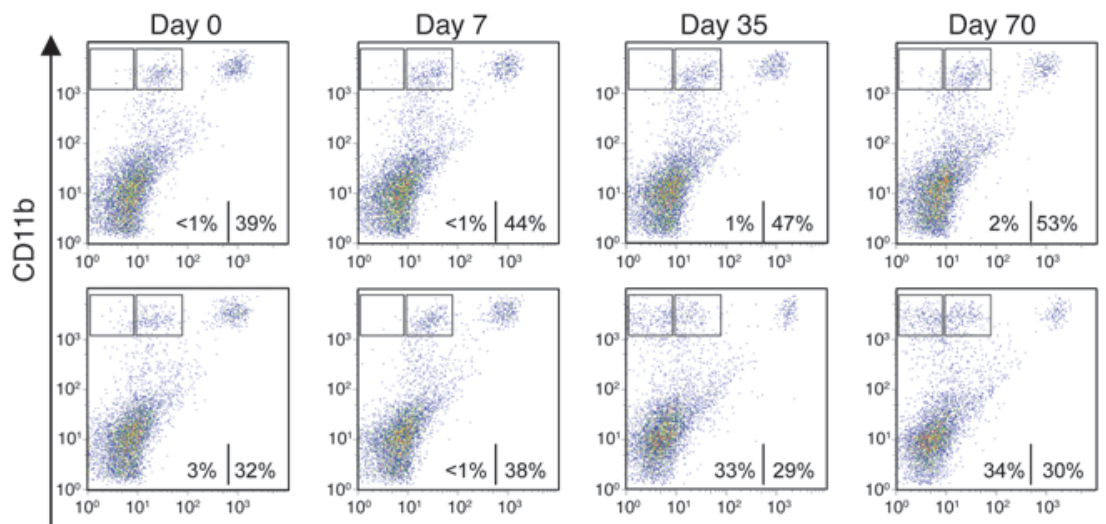

Oxa-colitis

(n)

B

Gr1

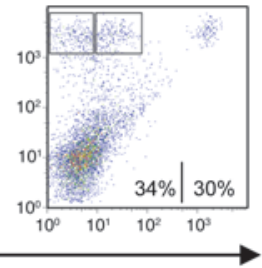

$\mathrm{AOM}+$ oxa-colitis
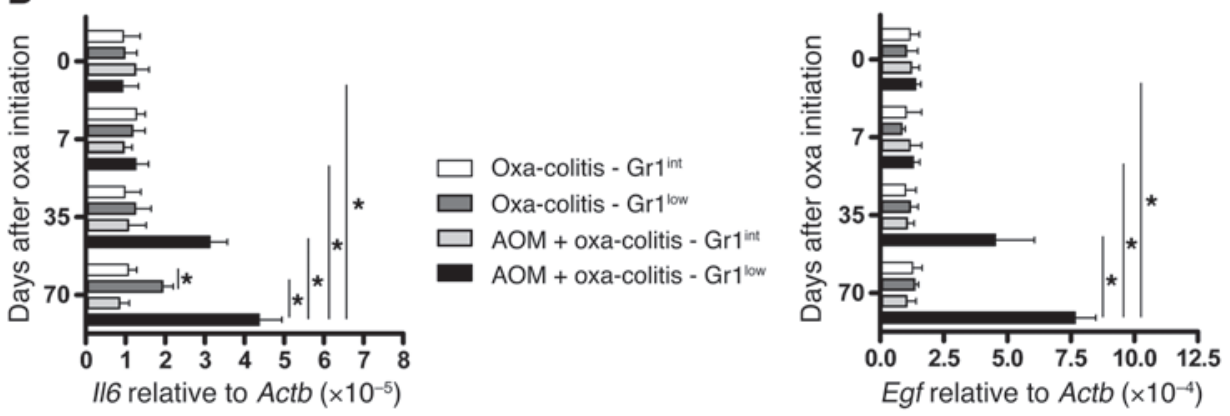

C

xa-colitis - Gr1

$\square$ Oxa-colitis - Gr1 $1^{\text {low }}$

$\square \mathrm{AOM}+$ oxa-colitis - Gr1 $1^{\text {int }}$

- $\mathrm{AOM}+$ oxa-colitis - Gr1 $1^{\text {low }}$

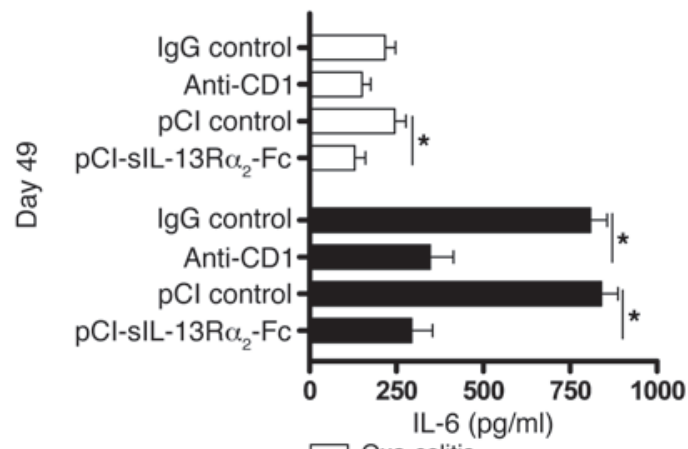

$\square$ Oxa-colitis

aOM + oxa-colitis

D $\quad \mathrm{AOM}+$ oxa-colitis

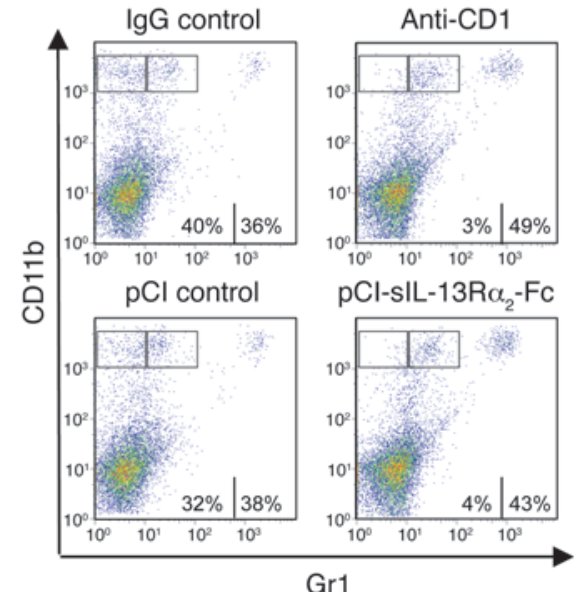

E
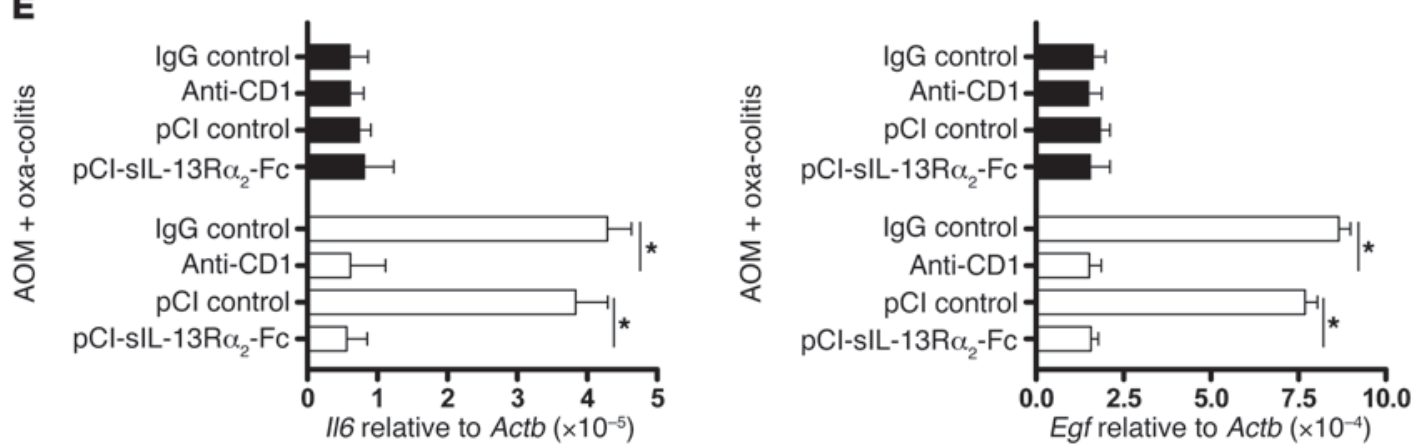

$\mathrm{F} 4 / 80+\mathrm{CD} 11 \mathrm{~b}{ }^{\text {high }} \mathrm{Gr} 1{ }^{\text {intermediate }}$

$\mathrm{F} 4 / 80^{+} \mathrm{CD}_{11} \mathrm{~b}^{\text {high }} \mathrm{Gr} 1^{\text {low }}$ 


\section{Figure 4}

Macrophage populations during chronic oxa-colitis and chronic oxacolitis with AOM-induced tumors. (A) Cells were extracted from the lamina propria and stained with anti-F4/80, anti-CD11b, and anti-Gr1 antibody. The blot shown is gated on $\mathrm{F} 4 / 80^{+}$cells. Percentages denote the percentages of $\mathrm{F} 4 / 80^{+} \mathrm{CD} 11 \mathrm{~b}$ high $\mathrm{Gr} 1$ low (left numbers) and $\mathrm{F} 4 / 80^{+} \mathrm{C}$

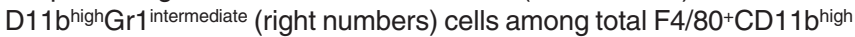
cells. (B) I/6 and Egf mRNA expression of $\mathrm{F} 4 / 80^{+} \mathrm{CD} 11 \mathrm{~b}^{\text {high }} \mathrm{Gr} 1^{\text {low }}$ and $\mathrm{F} 4 / 80^{+} \mathrm{CD} 11 \mathrm{~b}^{\text {high }} \mathrm{Gr} 1^{\text {intermediate }}$ cells. Colonic cells were isolated by flow cytometric sorting. I/6 and Egf mRNA was determined by quantitative PCR. Data shown are mean $\pm \operatorname{SEM}\left(n=3-5\right.$ mice per group). ${ }^{*} P \leq 0.05$. (C) IL-6 production on day 49 of oxa-colitis with AOM-induced tumors after treatment with $\mathrm{pCl}-\mathrm{sIL}-13 \mathrm{R} \alpha_{2}-\mathrm{Fc}$ or anti-CD1 antibody. Cells were extracted from the lamina propria. Cytokine concentrations were determined in culture supernatants by ELISA. Data shown are mean \pm SEM from individual cultures of cells derived from 2 separate experiments ( $n=6$ mice per group). ${ }^{*} P \leq 0.05$. (D) Macrophage populations on day 49 of oxa-colitis with AOM-induced tumors after treatment with pCl-slL$13 \mathrm{R} \alpha_{2}-\mathrm{Fc}$ or anti-CD1 antibody. Cells were extracted from the lamina propria and stained with anti-F4/80, anti-CD11b, and anti-Gr1 antibody. The blot shown is gated on $\mathrm{F} 4 / 80^{+}$cells. Percentages denote the percentages of $\mathrm{F} 4 / 80^{+} \mathrm{CD} 11 \mathrm{~b}^{\text {high }} \mathrm{Gr} 1^{\text {low }}$ (left numbers) and $\mathrm{F} 4 / 80^{+} \mathrm{CD} 11 \mathrm{~b}^{\text {high }}$ Gr1 intermediate (right numbers) cells among total $\mathrm{F} 4 / 80^{+} \mathrm{CD} 11 \mathrm{~b}^{\text {high }}$ cells. (E) I/6 and Egf mRNA expression of $\mathrm{F} 4 / 80^{+} \mathrm{CD} 11 \mathrm{~b}^{\text {high }} \mathrm{Gr} 1^{\text {low }}$ and $\mathrm{F} 4 / 80^{+}$ CD11 bigh $\mathrm{Gr} 1$ intermediate cells on day 49 of oxa-colitis with AOM-induced tumors after treatment with $\mathrm{pCl}-\mathrm{SIL}-13 \mathrm{R} \alpha_{2}-\mathrm{Fc}$ or anti-CD1 antibody. Colonic cells were isolated by flow cytometric sorting. II6 and Egf mRNA was determined by quantitative PCR. Data shown are mean \pm SEM ( $n=3-5$ mice per group). ${ }^{*} P \leq 0.05$.

cells in mice with oxa-colitis without tumors. As shown in Supplemental Figure 5, in contrast to the inhibitory effect of anti-IL-6 on the number of tumor nodules shown in Figure 2E, anti-EGF did not change the number of tumor nodules but did reduce the average diameter of tumor nodules.

To further investigate the nature of the $\mathrm{F} 4 / 80^{+} \mathrm{CD} 11 \mathrm{~b}^{\text {high }} \mathrm{Gr} 1^{\text {low }}$ and $\mathrm{F} 4 / 80^{+} \mathrm{CD} 11 \mathrm{~b}^{\text {high }} \mathrm{Gr} 1^{\text {intermediate }}$ cells, we compared their expression of mRNA associated with M1 or M2 macrophages. As shown in Supplemental Figure 6, we found that $\mathrm{F} 4 / 80^{+} \mathrm{CD} 11 \mathrm{~b}^{\text {high }} \mathrm{Gr} 1^{\text {low }}$ macrophages expressed increased levels of scavenger receptor B1 (Scarb1), increased levels of mannose receptor 1 (Mrc1), and reduced levels of Tnf and Nos 2 as compared with F4/80 CD $11 \mathrm{~b}$ ${ }^{\text {high }} \mathrm{Gr} 11^{\text {intermediate }}$ cells, whereas arginase expression levels were similar in the 2 populations; these findings suggested that the $\mathrm{F} 4 / 80^{+} \mathrm{CD} 11 \mathrm{~b}^{\text {high }} \mathrm{Gr} 1^{\text {low }}$ cells have an M2-like phenotype as compared with $\mathrm{F} 4 / 80^{+} \mathrm{CD} 11 \mathrm{~b}^{\text {high }} \mathrm{Gr} 1^{\text {intermediate }}$ cells

In a final series of studies along these lines, we investigated the impact of abrogation of oxa-colitis by the inhibition of IL-13 or NKT cells on LPMC IL-6 production. As shown in Figure 4C, IL-6 production by LPMCs in mice with oxa-colitis with AOM-induced tumors was much higher than that by LPMCs in mice with oxa-colitis without tumors, and in both cases, IL-6 production was significantly inhibited in mice after treatment of mice with the colitis-abrogating agents, anti-CD 1 antibody and pCI-sIL-13R $\alpha_{2}$-Fc (beginning on day 20). In addition, as shown in Figure 4D, such treatment led to decreased numbers of $\mathrm{F} 4 / 80^{+} \mathrm{CD} 11 \mathrm{~b}^{\text {high }} \mathrm{Gr} 1^{\text {low }}$ macrophages in LPMCs and, as shown in Figure 4E, decreased production of $I l 6$ and Egf mRNA by residual $\mathrm{F} 4 / 80^{+} \mathrm{CD} 11 \mathrm{~b}^{\text {high }} \mathrm{Gr} 1^{\text {low }}$ macrophages.

Taken together, these data show that tumor growth in mice with oxa-colitis is associated with the presence of increased numbers of $\mathrm{F} 4 / 80^{+} \mathrm{CD} 11 \mathrm{~b}^{\text {high }} \mathrm{Gr} 1^{\text {low }}$ cells that produce IL- 6 and EGF. These data thus point out an important distinction between tumor formation in the oxa-colitis and DSS-colitis models: as shown in Supplemental Figure $7 \mathrm{~A}, \mathrm{~F} 4 / 80^{+} \mathrm{CD} 11 \mathrm{~b}^{\text {high }} \mathrm{Gr} 1^{\text {low }}$ cells were not present in the colons of mice with DSS-colitis with AOM-induced tumors, and, as shown in Supplemental Figure 7B, IL-13 levels in mice with DSS-colitis were quite low compared with those in mice with oxa-colitis on day 49.

Impaired TLR signaling in Myd88 ${ }^{-/-}$mice leads to delayed but ultimately robust chronic oxa-colitis that supports AOM-induced tumor formation. In further studies, we examined the role of innate signaling in the development of oxa-colitis with the use of $M y d 88^{-1-}$ mice. As shown in Figure 5A, WT mice subjected to oxazolone administration lost more weight than $M y d 88^{-/-}$mice during the first 3 weeks of colitis induction, but after that period the weight of mice in the 2 groups converged and was maintained at a plateau well below the starting weight. In contrast, whereas WT mice administered AOM displayed a biphasic weight loss (as seen before in Figure 1A),

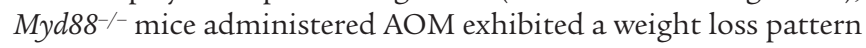
similar to that of WT mice not administered AOM.

These weight curves correlated with histologic studies of the colon. Thus, as shown in Supplemental Figure 8, A and B, WT mice displayed severe inflammation in the initial phase of oxa-colitis, whereas

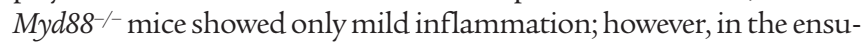
ing weeks, the levels of inflammation in WT and $\mathrm{Myd} \mathrm{W} 8^{-/-}$mice were similar to those seen previously in chronic oxa-colitis. In addition,

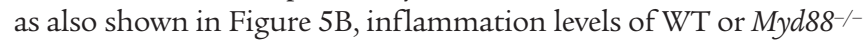
mice with oxa-colitis and administration of AOM again converged to a similar level of severity in the ensuing weeks. With respect to

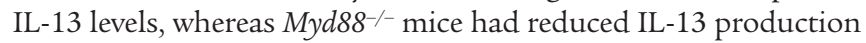
as compared with that of WT mice in the early phase of oxa-colitis

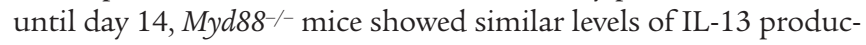
tion by LPMCs on day 35 and 56 (Figure 5C and Supplemental Figure 8C). Similarly, as shown in Figure 5D and Supplemental Figure

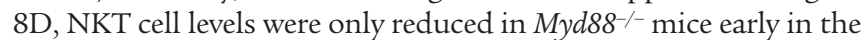
course of disease. These data indicate that while oxa-colitis is delayed in $M y d 88^{-/-}$mice, the latter ultimately develop full-blown oxa-colitis. The delay observed may be due to the fact that $M y d 88^{-/-}$mice cannot mount a vigorous, increased IFN- $\gamma$ response that characterizes very early chronic oxa-colitis in WT mice (data not shown).

Although mice with Myd88 deficiency developed full-blown chronic oxa-colitis after the first 3 weeks of oxazolone administration, they nevertheless exhibited a profound loss in the ability to support the development of AOM-induced tumors. Thus, as

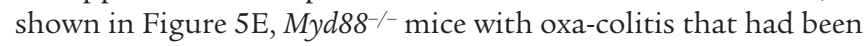
administered AOM exhibited almost no tumor nodules on day 49, whereas WT mice developed the number of tumors seen in earlier studies. In addition, the size of each remaining nodule in $M y d 88^{-/-}$ mice was reduced: on day 49, the average tumor diameter of WT mice was $3.3 \pm 0.8 \mathrm{~mm}$ (25 tumors evaluated) and that of $M y d 88^{-/-}$ mice was $1.3 \pm 0.4 \mathrm{~mm}$ (10 tumors evaluated). Further observation of $M y d 88^{-/-}$mice to 120 days after initial AOM administration revealed persistent reduction of tumor incidence and tumor size.

Relation of lack of tumor formation in Myd88-1- mice to IL-6. To investigate the reason for the reduction in tumor formation in Myd $88^{-1-}$ mice, we first determined whether the reduction could be related to an effect on IL- 6 production. To this end, we recon-

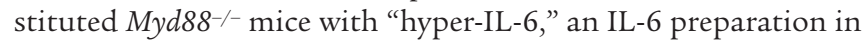
which IL-6 is covalently linked to soluble IL-6 receptor (IL-6R) and which has previously been shown to exhibit heightened IL-6 signaling via "IL-6 trans-signaling" (14,34-36). As shown in Figure 6A, the administration of hyper-IL-6 ( $2 \mu \mathrm{g}$ i.p. each week, beginning 
A
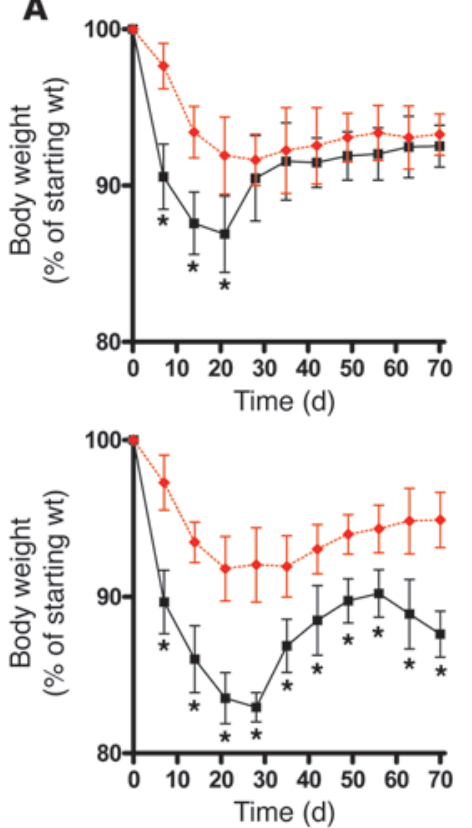

C

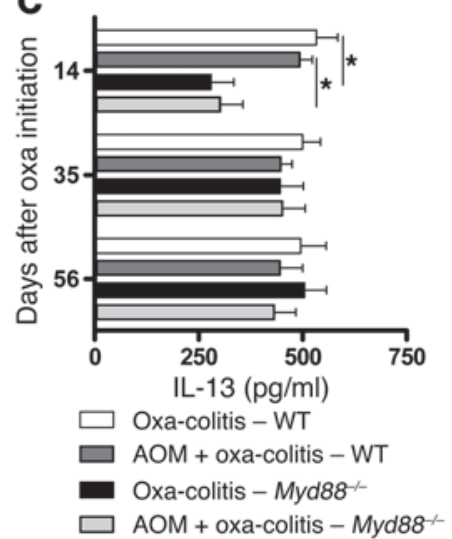

B

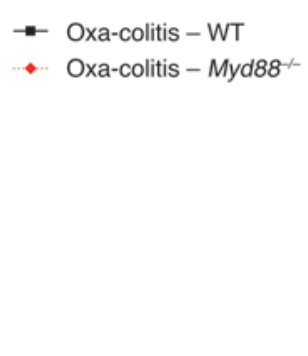

$\rightarrow$ AOM + oxa-colitis - WT

- AOM + oxa-colitis - Myd88

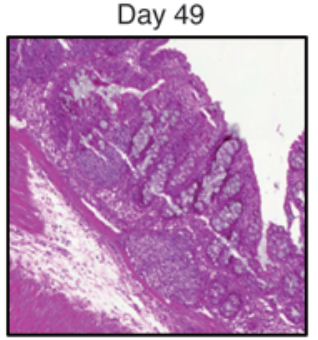

Oxa-colitis WT

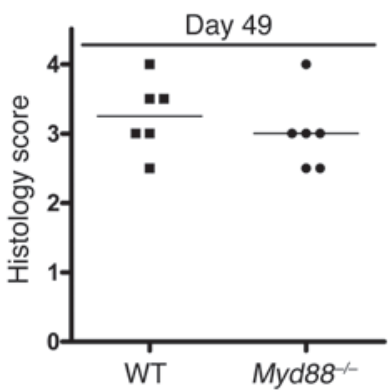

E
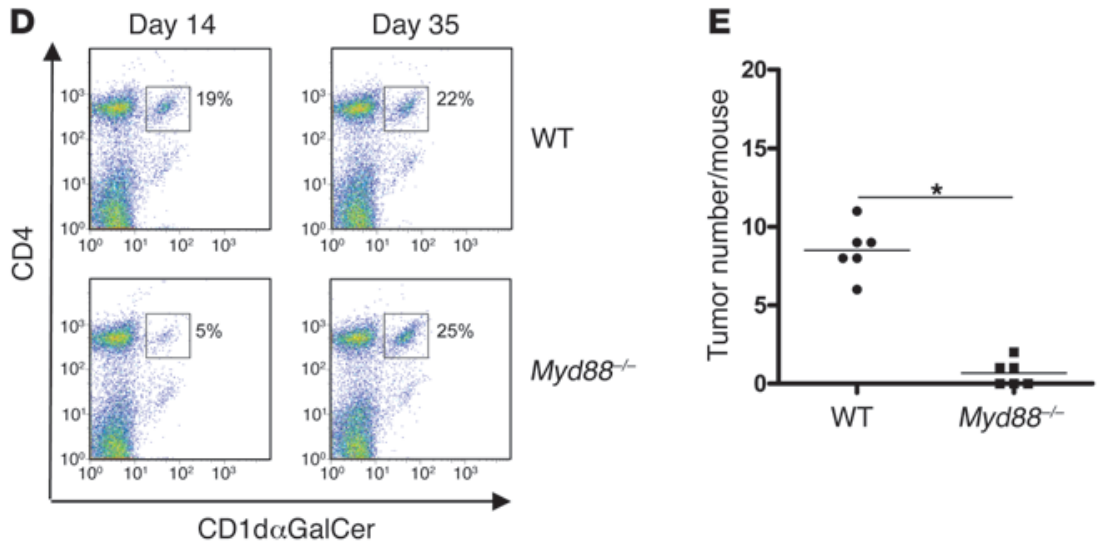

Day 49

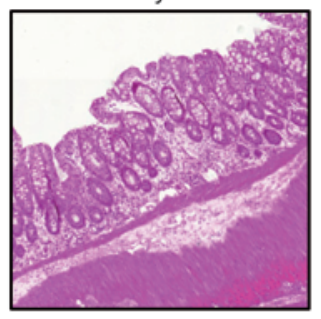

Oxa-colitis Myd88-

\section{Figure 5}

The acute phase of oxa-colitis is dependent on MyD88. (A) Body weight in WT and Myd88-/- mice. Data shown are mean \pm SEM $(n=6$ mice per group). ${ }^{*} P \leq 0.05$ tested for WT group and $M y d 88^{-1-}$ group. (B) H\&E staining of representative inflamed areas of colon sections (original

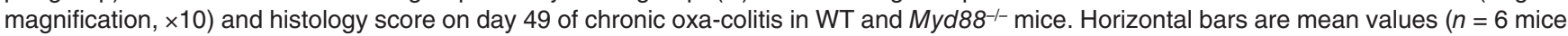
per group). Individual symbols represent 1 mouse. (C) IL-13 production of oxa-colitis and oxa-colitis with AOM-induced tumors in WT and Myd88-/- mice. Cells were extracted from the lamina propria. Cytokine concentrations were determined in culture supernatants by ELISA. Data shown are mean \pm SEM from individual cultures of cells derived from mice in 2 separate experiments $\left(n=6\right.$ mice per group). ${ }^{*} P \leq 0.05$. (D) NKT cell expression of oxa-colitis in WT and $M y d 88^{-/-}$mice. Cells were extracted from the lamina propria and stained with anti-CD4 antibody and CD1d $\alpha$ GalCer tetramers. Percentages denote the percentages of CD4+CD1d $\alpha$ GalCer ${ }^{+}$cells among total CD4+ cells. (E) Number of tumor nodules on day 49 of oxa-colitis with AOM-induced tumors in WT and Myd88-/ mice. Horizontal bars are mean values ( $n=6$ mice per group). Individual symbols represent 1 mouse. ${ }^{\star} P \leq 0.05$.

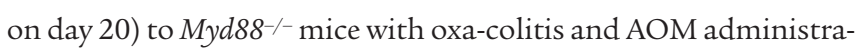
tion resulted in a weight loss pattern similar to that of WT mice, which included a second phase of weight loss indicative of tumor growth and obstruction. In addition, as shown in Figure 6B,

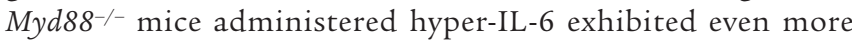
tumor nodules in the colon on day 49 than WT mice. Myd88-1mice not administered hyper-IL-6 were almost completely free of tumors. On day 49, the average tumor diameter of WT mice was $3.8 \pm 1 \mathrm{~mm}$ (25 tumors evaluated), that of $M y d 88^{-/-}$mice was $1.1 \pm 0.3 \mathrm{~mm}$ (10 tumors evaluated), and that of $\mathrm{Myd}^{-8^{--}}$mice with hyper-IL-6 treatment was $4.0 \pm 0.6 \mathrm{~mm}$ (25 tumors evaluated). These data show that the failure of $M y d 88^{-/-}$mice to support AOM-induced tumor growth is due, at least in part, to reduced IL-6 production. Parenthetically, they also show that such failure was not due to initially decreased inflammation, since the mice retained the ability to develop tumors once the deficiency in IL-6 secretion was corrected. As shown in Supplemental Figure 9, the administration of recombinant IL-6, which is not capable of inducing IL-6 trans-signaling, also led to regained ability to manifest tumor growth; however, as expected, the extent of restoration 
A

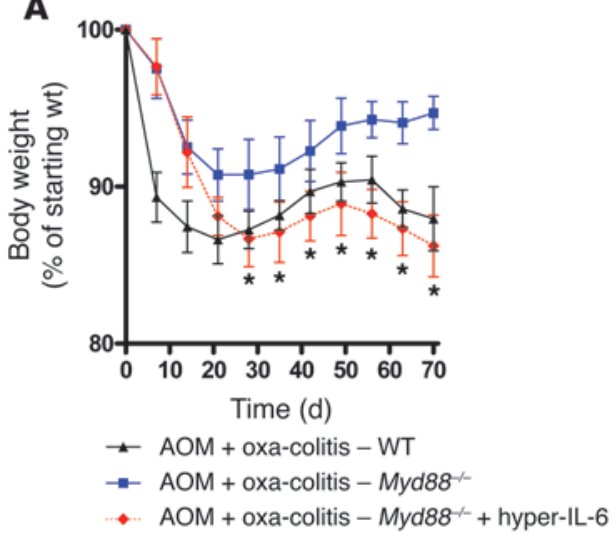

D

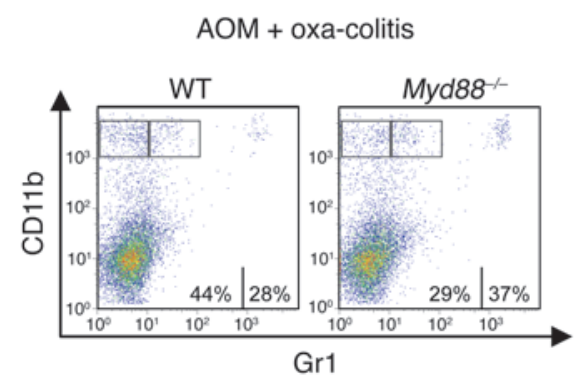

B

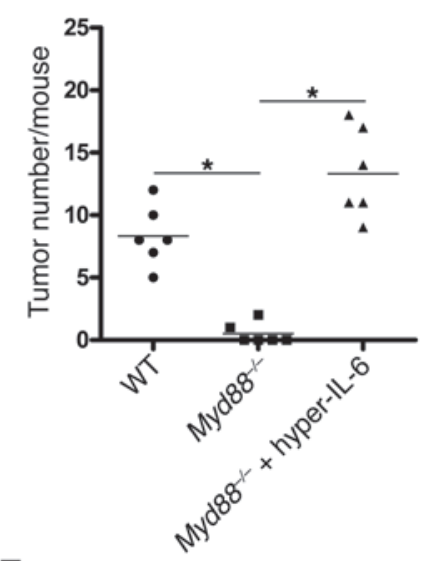

E

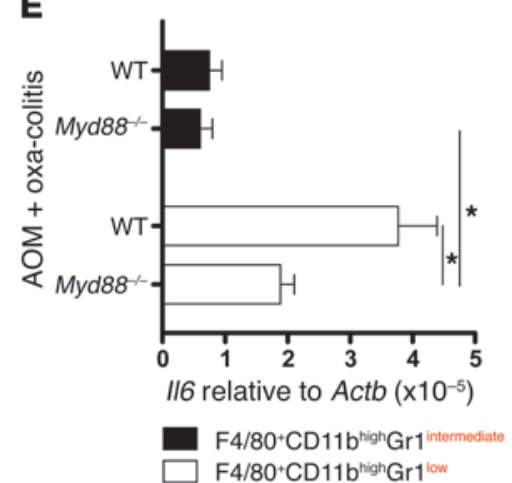

C
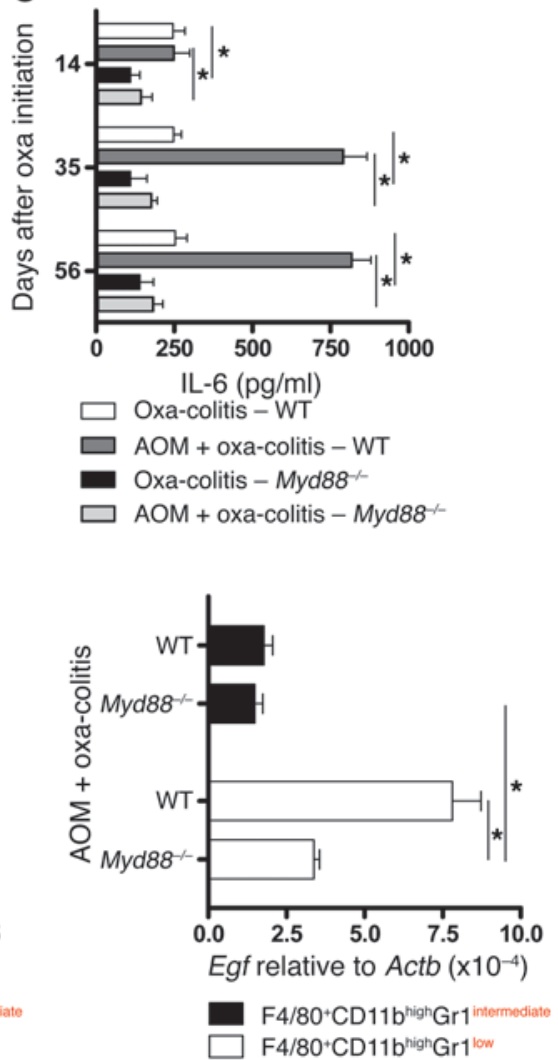

Figure 6

Tumor formation is dependent on IL-6. (A) Body weight measured after reconstitution of Myd88-1- mice with hyper-IL-6. Data shown are

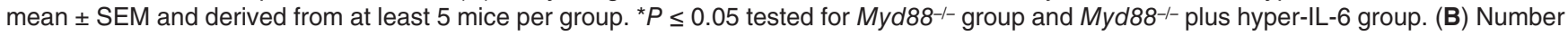
of tumor nodules on day 49 of oxa-colitis with AOM-induced tumors after reconstitution of $M y d 88^{-/-}$mice with hyper-IL-6. Horizontal bars are mean values ( $n=6$ mice per group). Individual symbols represent 1 mouse. ${ }^{*} P \leq 0.05$. (C) IL-6 production of oxa-colitis and oxa-colitis with AOMinduced tumors in WT and $M y d 88^{-1-}$ mice. Cells were extracted from the lamina propria. Cytokine concentrations were determined in culture supernatants by ELISA. Data shown are mean \pm SEM from individual cultures of cells derived from mice in 2 separate experiments $(n=6$ mice per group). ${ }^{*} P \leq 0.05$. (D) Distribution of macrophage populations on day 49 of oxa-colitis with AOM-induced tumors in WT and $M y d 88^{-1-}$ mice. Cells were extracted from the lamina propria and stained with anti-F4/80, anti-CD11b, and anti-Gr1 antibody. The blot shown is gated on F4/80+ cells. Percentages denote the percentages of $\mathrm{F} 4 / 80^{+} \mathrm{CD} 11 \mathrm{~b}^{\text {high }} \mathrm{Gr} 1^{\text {low }}$ (left numbers) and $\mathrm{F} 4 / 80^{+} \mathrm{CD} 11 \mathrm{~b}^{\text {high }} \mathrm{Gr} 1^{\text {intermediate }}$ (right numbers) cells among total $\mathrm{F} 4 / 80^{+} \mathrm{CD} 11 \mathrm{~b}^{\text {high }}$ cells. (E) //6 and Egf mRNA expression of $\mathrm{F} 4 / 80^{+} \mathrm{CD} 11 \mathrm{~b}^{\text {high }} \mathrm{Gr} 1^{\text {low }}$ and $\mathrm{F} 4 / 80^{+} \mathrm{CD} 11 \mathrm{~b}^{\text {high }} \mathrm{Gr} 1^{\text {intermediate }}$ cells on day 49 of oxa-colitis with $\mathrm{AOM}$-induced tumors after treatment with $\mathrm{pCl}-\mathrm{sIL}-13 \mathrm{R} \alpha_{2}-\mathrm{Fc}$ or anti-CD1 antibody. Colonic F4/80+CD11bigh Gr1low and $\mathrm{F} 4 / 80+\mathrm{CD} 11 \mathrm{~b}$ high $\mathrm{Gr} 1$ intermediate cells were isolated by flow cytometric sorting. //6 and Egf mRNA expression was determined by quantitative PCR. Data shown are mean \pm SEM $\left(n=3-5\right.$ mice per group). ${ }^{*} P \leq 0.05$.

with this material was slightly reduced in comparison with that obtained with hyper-IL-6, presumably due to its reduced signaling capacity relative to hyper-IL- 6 .

In a second approach to exploring the reason for lack of tumor development in $M y d 88^{-/-}$mice, we measured cytokine production by

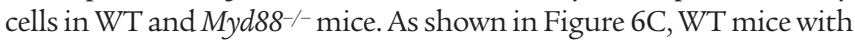
oxa-colitis that had been administered AOM had cells producing

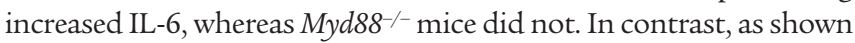

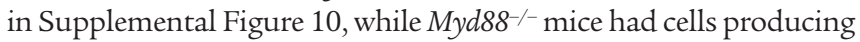
slightly decreased amounts of TNF- $\alpha$ during the early phase of oxacolitis, on days 35 and 56 of colitis these mice produced TNF- $\alpha$ in amounts comparable to those of WT animals. In further studies along these lines, we determined the presence of $\mathrm{F} 4 / 80^{+} \mathrm{CD} 11 \mathrm{~b}^{\text {high }} \mathrm{Gr} 1^{\text {low }}$ macrophages on day 49 during chronic oxa-colitis in WT and Myd88-/- mice. As shown in Figure 6, D and E, we found that while the inflammation in $\mathrm{Myd} 88^{-/-}$mice gave rise to the presence of only slightly reduced levels of $\mathrm{F} 4 / 80^{+} \mathrm{CD} 11 \mathrm{~b}^{\text {high }} \mathrm{Gr} 1^{\text {low }}$ macrophages in the colons of mice with oxa-colitis on day 49 , these macrophages produced greatly reduced amounts of $I l 6$ and Egf mRNA. These data suggest that production of IL- 6 and EGF by F4/80 $\mathrm{CD} 11 \mathrm{~b}^{\text {high }} \mathrm{Gr} 1^{\text {low }}$ macrophages is dependent on MyD88 signaling.

Since IL-1 $\beta$-mediated stimulatory effects also depend on the adaptor protein MyD88, we also explored the possibility that impaired IL- $1 \beta$ signaling accounts for the lack of tumor formation in $\mathrm{Myd88^{-/- }}$ mice with chronic oxa-colitis and subject to AOM tumor induction. As shown in Supplemental Figure 11A, we found that $\mathrm{F} 4 / 80^{+} \mathrm{CD} 11 \mathrm{~b}^{\text {high }} \mathrm{Gr} 1^{\text {low }}$ macrophages obtained from mice with oxa-colitis and tumors (on day 49 of colitis) do not produce IL-6 (above baseline) in response to IL-1 $\beta$ stimulation but do so in response to TLR4 and TLR2 stimulation, especially the latter. Furthermore, as shown in Supplemental Figure 11, B and $\mathrm{C}$, we found that in vivo administration of IL-1R1 antibody 
A

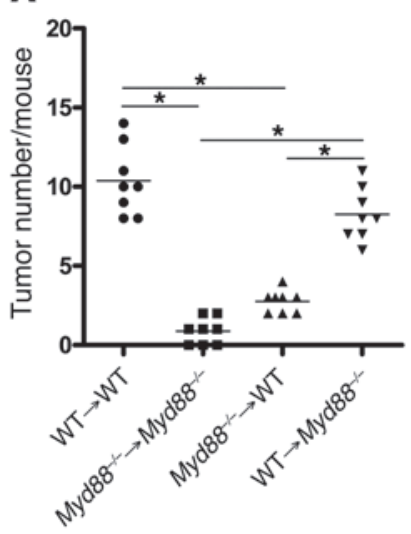

C

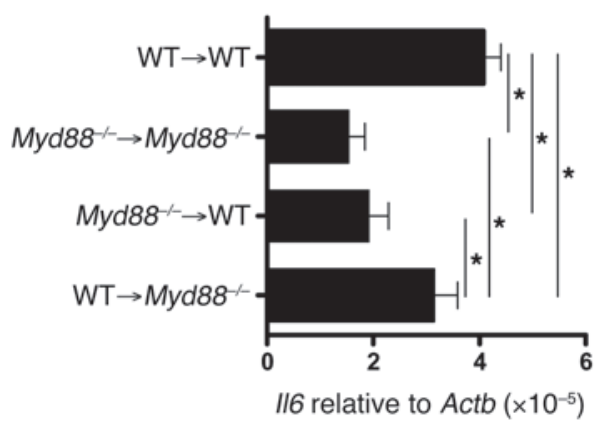

B

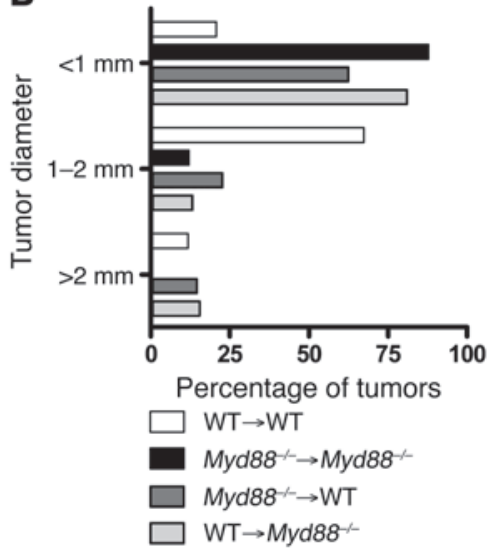

D

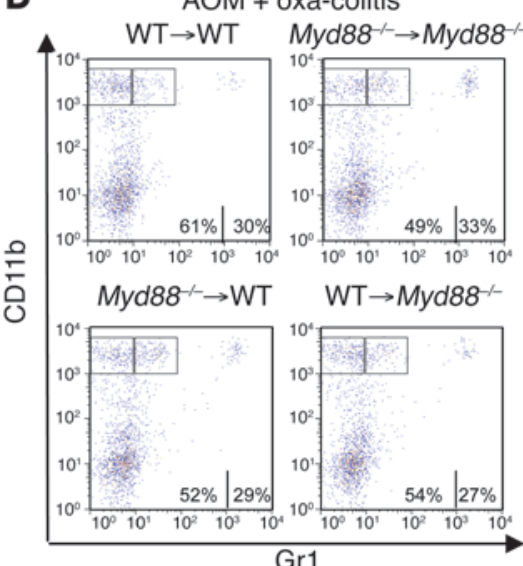

\section{Figure 7}

Hematopoietic Myd88 deficiency reduces tumor number and tumor size. (A) Number of tumor nodules on day 49 of oxacolitis with AOM-induced tumors in BM chimeric mice. Horizontal bars are mean values ( $n=8$ mice per group). Individual symbols represent 1 mouse. ${ }^{*} P \leq 0.05$. (B) Diameter of tumor nodules on day 49 of oxa-colitis with AOM-induced tumors in BM chimeric mice. Measurements of tumor nodules refer to diameter and were made using a digitally obtained image of the whole tissue section. Evaluation was performed using the Mirax Viewer software (Carl Zeiss AG). (C) //6 mRNA expression of $\mathrm{F} 4 / 80^{+} \mathrm{CD} 11 \mathrm{~b}^{\text {high }} \mathrm{Gr} 1^{\text {low }}$ cells on day 49 of oxa-colitis with AOM-induced tumors in $\mathrm{BM}$ chimeric mice. Colonic $\mathrm{F} 4 / 80^{+} \mathrm{CD} 11 \mathrm{~b}^{\text {high }} \mathrm{Gr} 1$ low cells were isolated by flow cytometric sorting. $/ 16$ mRNA expression was determined by quantitative PCR. Data shown are mean \pm SEM $(n=3-5$ mice per group). ${ }^{*} P \leq 0.05$. (D) Distribution of macrophage populations on day 49 of oxa-colitis AOM-induced tumors. Cells were extracted from the lamina propria and stained with anti-F4/80, anti-CD11b, and anti-Gr1 antibody. The blot shown is gated on $\mathrm{F} 4 / 80^{+}$cells. Percentages denote the percentages of $\mathrm{F} 4 / 80^{+} \mathrm{CD} 11 \mathrm{~b}^{\text {high }} \mathrm{Gr} 1^{\text {low }}$ (left numbers) and $\mathrm{F} 4 / 80+\mathrm{CD} 11 \mathrm{~b}$ high $\mathrm{Gr} 1$ intermediate (right numbers) cells among total $\mathrm{F} 4 / 80^{+}$ CD11bigh cells. to mice with oxa-colitis and tumors $(100 \mu \mathrm{g}$ i.p. every other day, beginning of day 20 of colitis) reduced neither the level of inflammation nor the number of tumors on day 49 of colitis. Finally, as shown in Supplemental Figure 11D, the expression of IL-13 and IL-6 in mice with chronic oxa-colitis and tumors was not affected by anti-IL-1R1 administration. To determine whether IL-18, a cytokine affecting epithelial cell integrity, was involved in tumor formation, we measured IL-18 levels during the period of AOMinduced tumor development and maintenance. As shown in Supplemental Figure 12, we found no differences in IL-18 expression in the intestines of mice with chronic inflammation and chronic inflammation with tumor growth. Thus, IL-18 production was likely not involved in tumor generation.

Relative effects of Myd88 deficiency in hematopoietic cells and nonbematopoietic cells on tumor formation. To determine whether the effect of Myd88 deficiency on tumor formation was due to a defect in hematopoietic cells (i.e., macrophages) or nonhematopoietic cells (i.e., epithelial cells) or both types of cells, we generated BM chimeric mice that expressed Myd88 deficiency in either hematopoietic cells or nonhematopoietic cells. Chimerism was evaluated by the percentage of $\mathrm{dsRed}^{+} \mathrm{CD} 45^{+}$cells in spleens of chimeras 8 weeks after transplantation. As shown in Supplemental Figure 13, we found that the degree of chimerism achieved in these studies was approximately $95 \%$.

As shown in Figure 7, A-C, the number of tumors in the Myd88-/- $\rightarrow$ WT chimeras was only modestly (but nevertheless significantly) greater than seen in $M y d 88^{-/-} \rightarrow M y d 88^{-/-}$mice, and tumor nodule diameter as well as $\mathrm{F} 4 / 80^{+} \mathrm{CD} 11 \mathrm{~b}^{\text {high }} \mathrm{Gr} 1^{\text {low }}$ macrophage $I l 6$ production in the 2 chimeras was similar. This indicates that hematopoietic (macrophage) loss of MyD88 signaling led to major loss of tumor-support function in spite of intact nonhematopoietic (epithelial cell) MyD88 signaling. On the other hand, the number of tumor nodules in WT $\rightarrow$ Myd88-/- chimeras was modestly but significantly fewer than the number of tumor nodules than WT $\rightarrow$ WT mice; in addition tumor, diameter was lower and $I l 6$ production by $\mathrm{F} 4 / 80^{+} \mathrm{CD} 11 \mathrm{~b}^{\text {high }} \mathrm{Gr} 1^{\text {low }}$ macrophages was significantly decreased in the former chimeric mice. Thus, nonhematopoietic (epithelial) loss of MyD88 signaling had a clear effect on tumor growth, particularly as such signaling loss related to tumor nodule size. The most reasonable interpretation of the combined data is that tumor growth is most dependent on MyD88 signaling in macrophages but that MyD88 signaling in epithelial cells also contributes to such growth, particularly with respect to tumor nodule size. Finally, it should be noted that percentage of $\mathrm{F} 4 / 80^{+} \mathrm{CD} 11 \mathrm{~b}^{\text {high }} \mathrm{Gr} 1^{\text {low }}$ cells in the lamina propria of WT and chimeric mice (including the $\mathrm{Myd} 88^{-/-} \rightarrow$ Myd $88^{-/-}$chimeras) was similar, suggesting that the appearance of these cells in AOM-induced tumor formation is not dependent on MyD88 signaling (Figure 7D).

Tumor immunosurveillance in chronic oxa-colitis. In previous studies, it has been shown that $\mathrm{CD}^{+}$cytotoxic $\mathrm{T}$ cells specific for tumor cells limit tumor growth (immunosurveillance), but NKT cells producing IL-13 stimulate Gr- $1^{\text {intermediate }}$ macrophages to produce TGF- $\beta 1$, which blocks such cytotoxic cells (counter-immunosurveillance) (37-39). In that NKT cells responsible for chronic 
A

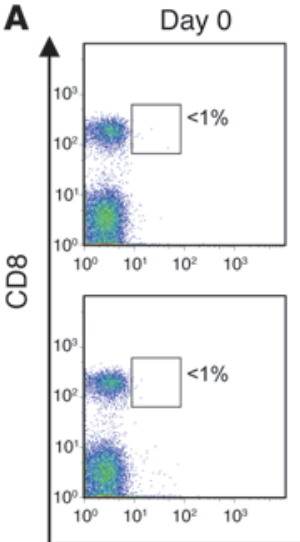

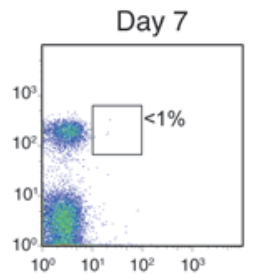
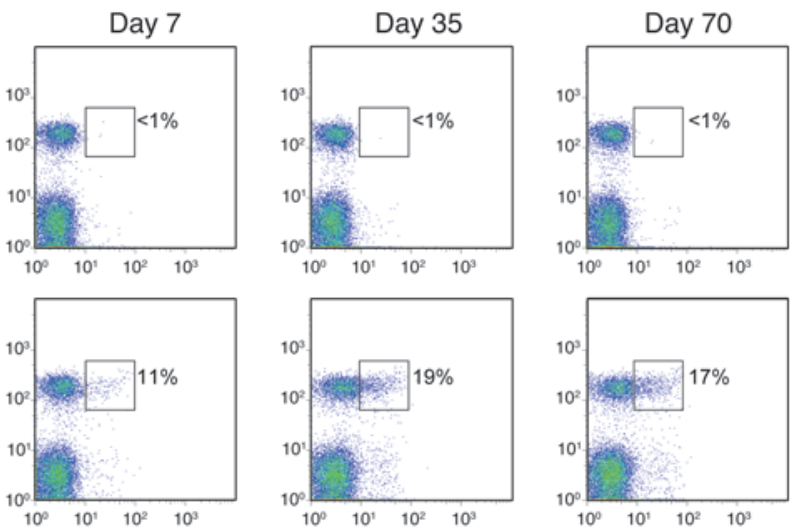

Oxa-colitis

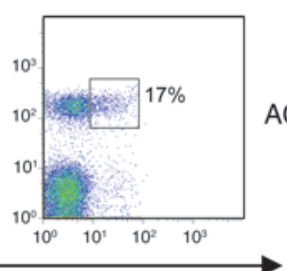

CD103

B $\mathrm{AOM}+$ oxa-colitis

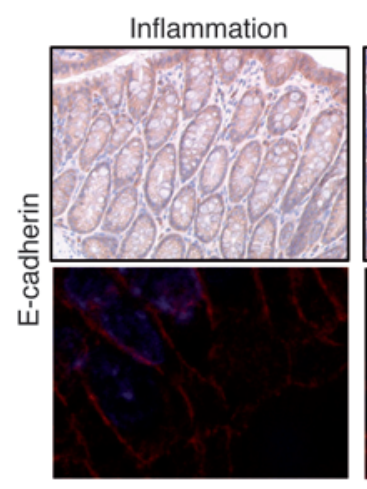

$$
\text { D }
$$

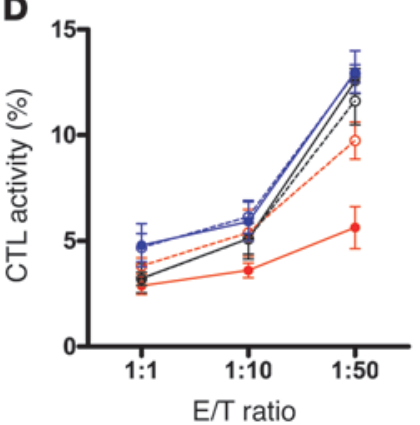

$\mathrm{AOM}+$ oxa-colitis

Tumor

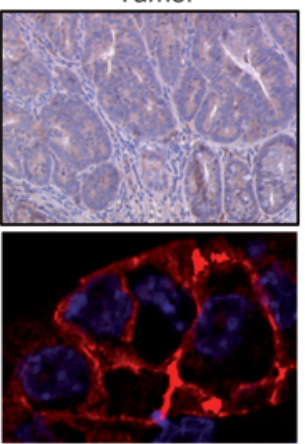

-a. Anti-TGF

$\rightarrow$ IgG control

-a. Gr1 $1^{\text {intermediate }}+$ anti-TGF

$\rightarrow \mathrm{Gr} 1^{\text {intermodiato }}+\mathrm{IgG}$ control

-a. $\mathrm{Gr}^{\text {low }}+$ anti-TGF

- $\mathrm{Gr}^{1 \mathrm{low}}+\lg \mathrm{G}$ control

Figure 8

Tumor immunosurveillance is mediated by $\mathrm{CD} 8^{+} \mathrm{CD} 103^{+} \mathrm{T}$ cells. (A) $\mathrm{CD} 8^{+} \mathrm{CD} 103^{+} \mathrm{T}$ cell expression during oxa-colitis and oxa-colitis with AOM-induced tumors. Cells were extracted from the lamina propria and stained with anti-CD8 and anti-CD103 antibody. Percentages denote the percentages of $\mathrm{CD}^{+}{ }^{+} \mathrm{CD} 103^{+}$cells among total CD8+ cells. (B) Immunohistochemistry/immunofluorescence staining for E-cadherin of representative inflamed areas and tumor areas of colon sections on day 49 of oxa-colitis with AOM-induced tumors (original magnification, $\times 15$ [top]; $\times 40$ [bottom]). (C) Cytotoxicity of CD8 ${ }^{+} \mathrm{T}$ cells against CT-26 cells or E-cadherin ${ }^{+}$(Ecad) CT-26 cells. CD8 $8^{+}$T cells were isolated from the colon on day 49 of oxa-colitis with AOM-induced tumors and cocultured with CT-26 cells or E-cadherin ${ }^{+}$CT-26 cells target cells. Cytotoxic activity was also determined in the presence of anti-CD103 antibody. Cytotoxicity was measured after 24 hours cytolytic activity. (D) Suppression of cytotoxicity of CD8+ T cells against E-cadherin ${ }^{+} \mathrm{CT}-26$ cells mediated by macrophage populations. CD8 ${ }^{+} \mathrm{T}$ cells and $\mathrm{F} 4 / 80^{+} \mathrm{CD} 11 \mathrm{~b}^{\text {high }} \mathrm{Gr} 1^{\text {low }}$ and $\mathrm{F} 4 / 80^{+} \mathrm{CD} 11 \mathrm{~b}^{\text {high }} \mathrm{Gr} 1^{\text {intermediate }}$ cells were isolated from the colon on day 49 of oxa-colitis with $\mathrm{AOM}$-induced tumors and cocultured with E-cadherin ${ }^{+}$CT-26 target cells. Cytotoxic activity was also determined in the presence of anti-TGF- $\beta 1$ antibody. Cytotoxicity was measured after 24 hours cytolytic activity. (E) Tgfb1 mRNA expression of F4/80+CD11 bhigh Gr1low (Gr1low) and F4/80+CD1 $1 \mathrm{~b}^{\text {high }} \mathrm{Gr} 1^{\text {intermediate }}$ ( $\mathrm{Gr} 1^{\text {intermediate }}$ ) cells on day 49 of oxa-colitis or oxa-colitis with $A O M$-induced tumors. Colonic F4/80+CD11bhigh $G r 1$ low and $\mathrm{F} 4 / 80+\mathrm{CD} 11 \mathrm{~b}^{\text {high }} \mathrm{Gr} 1$ intermediate cells were isolated by flow cytometric sorting. Tgfb1 mRNA expression was determined by quantitative PCR. Data shown are mean $\pm \operatorname{SEM}\left(n=3-5\right.$ mice per group). ${ }^{*} P \leq 0.05$. 
oxa-colitis produce IL-13, we determined whether counter-immunosurveillance occurs during AOM-induced tumor formation associated with this form of colitis.

In initial studies to explore this possibility, we determined $\mathrm{CD} 103^{+} \mathrm{CD}^{+} \mathrm{T}$ cell levels in the colonic cell populations obtained from (tumor-prone) areas of colons in mice with chronic oxa-colitis without and with $\mathrm{AOM}$-induced tumors at various time points. As shown in Figure 8A, cells from non-tumor-bearing colitic mice exhibit no $\mathrm{CD} 103^{+} \mathrm{CD} 8^{+} \mathrm{T}$ cells over the course of the colitis, whereas tumor-bearing colitic mice manifested a steadily increasing number of such cells. Since in previous studies interactions between cytotoxic CD8 ${ }^{+} \mathrm{T}$ cells bearing $\mathrm{CD} 103\left(\alpha_{\mathrm{E}} \beta_{7}\right)$ and tumor cell targets is facilitated by expression of the CD103 ligand, E-cadherin, on the target cells, we next determined the expression level of E-cadherin on epithelial cells using immunohistochemistry (40). As shown in Figure 8B, nontumorous colonic epithelial cells from mice with chronic oxa-colitis expressed only a basal level of E-cadherin, whereas tumor epithelial cells from mice with chronic oxacolitis with AOM injection expressed high levels of E-cadherin.

In further studies, we investigated the cytotoxic potential of $\mathrm{CD} 103^{+} \mathrm{CD}^{+} \mathrm{T}$ cells isolated from colonic tumor areas using (syngeneic) untransfected CT-26 colon epithelial tumor cells (without intrinsic E-cadherin expression) or CT26 cells transfected with an E-cadherin-expressing plasmid and therefore expressing surface E-cadherin. As shown in Figure $8 \mathrm{C}$, whereas the isolated $\mathrm{CD} 103^{+} \mathrm{CD}^{+} \mathrm{T}$ cells exhibited only minimal cytotoxicity for untransfected CT-26 cells, they exhibited substantial cytotoxicity for transfected (E-cadherinexpressing) CT-26 cells. In addition, cytotoxic killing of the E-cadherin $^{+}$cells was inhibited by the addition of anti-CD103 antibody to the culture. Verification of the importance of the CD103/E-cadherin interaction to the cytotoxicity of the isolated cells came from studies in which (allogeneic) CMT93 colon cancer cells, which constitutively express E-cadherin, were used as target cells. While in this cytotoxicity assay the basal level of cytotoxicity was increased (presumably due to allogenicity), the addition of anti-CD103 antibody again significantly reduced cytotoxicity (data not shown). Finally, to determine whether the $\mathrm{CD}^{+} \mathrm{T}$ cells appearing in mice with oxa-colitis bearing tumors inhibit tumor growth, we assessed tumor expression in mice administered anti-CD8 antibody, resulting in an approximately $80 \%$ decrease in the number of CD $8^{+}$cells in the spleen (data not shown). While such treatment did not lead to a change in the number of tumors, as shown in Supplemental Figure 14, it did lead to a significant increase in tumor nodule size. Thus, it was apparent that the $\mathrm{CD}^{+}$cells were exerting immunosurveillance of the tumors.

As alluded to above, the immunosurveillance exerted by $\mathrm{CD} 103^{+} \mathrm{CD}^{+}$cytotoxic $\mathrm{T}$ cells in the tumor tissue could potentially be neutralized by NKT cells producing IL-13 and inducing $\mathrm{F} 4 / 80^{+} \mathrm{CD} 11 \mathrm{~b}^{\text {high }} \mathrm{Gr} 1^{\text {intermediate }}$ cells to produce $\mathrm{TGF}-\beta 1$, the latter a cell present in the lamina propria of mice with oxa-colitis in the presence or absence of tumors. We therefore performed cytotoxicity assays of E-cadherin-expressing CT-26 cells in the presence and absence of $\mathrm{F} 4 / 80^{+} \mathrm{CD} 11 \mathrm{~b}^{\text {high }} \mathrm{Gr} 1^{\text {low }}$ and $\mathrm{F} 4 / 80^{+} \mathrm{CD}$ $11 \mathrm{~b}^{\text {high }} \mathrm{Gr} 1^{\text {intermediate }}$ cells isolated from tumor-bearing colonic tissue. As shown in Figure 8D, cytotoxicity was greatly diminished by the presence of $\mathrm{F} 4 / 80^{+} \mathrm{CD} 11 \mathrm{~b}^{\text {high }} \mathrm{Gr} 1^{\text {intermediate }}$ cells but not $\mathrm{F} 4 / 80^{+} \mathrm{CD} 11 \mathrm{~b}^{\text {high }} \mathrm{Gr} 1^{\text {low }}$ cells. In addition, as shown in Figure $8 \mathrm{E}$, $\mathrm{F} 4 / 80^{+} \mathrm{CD} 11 \mathrm{~b}^{\text {high }} \mathrm{Gr} 1^{\text {intermediate }}$ cells produce far more $\mathrm{Tg} f \mathrm{~b} 1$ than $\mathrm{F} 4 / 80^{+} \mathrm{CD} 11 \mathrm{~b}^{\text {high }} \mathrm{Gr} 1^{\text {low }}$ cells, and the decreased cytotoxicity seen in the presence of the latter cells was reversed by the presence of anti-TGF- $\beta 1$ antibody, thus accounting for the different ability of $\mathrm{F} 4 / 80^{+} \mathrm{CD} 11 \mathrm{~b}^{\text {high }} \mathrm{Gr} 1^{\text {low }}$ and $\mathrm{F} 4 / 80^{+} \mathrm{CD} 11 \mathrm{~b}{ }^{\text {high }} \mathrm{Gr} 1^{\text {intermediate }}$ cells to inhibit $\mathrm{CD}^{+} \mathrm{T}$ cell-mediated cytotoxicity.

Taken together, these data show that cytotoxic CD $103^{+} \mathrm{CD}^{+} \mathrm{T}$ cells, potentially capable of exerting immunosurveillance of tumor cells, do make their appearance in oxa-colitis with AOM-induced tumors and do limit tumor growth; however, the function of these cells is likely impeded by the presence of $\mathrm{F} 4 / 80^{+} \mathrm{CD} 11 \mathrm{~b}^{\text {high }} \mathrm{Gr} 1^{\text {intermediate }}$ macrophages, which produce TGF- $\beta 1$ and thereby inhibit the cytotoxic CD8 ${ }^{+} \mathrm{T}$ cells.

Myd88-/- mice exhibit reduced $C D 8^{+} T$ cell cytotoxicity. As shown in Supplemental Figure 15A, in contrast to WT mice with oxa-colitis

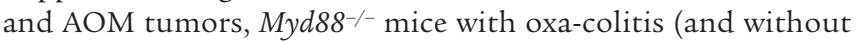

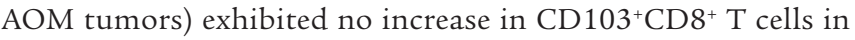
intestinal tissue (sampled on day 35 of colitis). In addition, as shown in Supplemental Figure 15B, the (largely CD103-) $\mathrm{CD}^{+} \mathrm{T}$ cells obtained from these mice exhibited dramatically reduced (but still present) cytotoxicity toward E-cadherin ${ }^{+}$CT- 26 cells. Importantly, this reduction in number and function of cytotoxic cells was not reversed by the administration of hyper-IL-6, an agent that restored the ability of the $M y d 88^{-/-}$mice to support tumor growth. Finally, we determined whether the limited cytotoxicity of the $\mathrm{CD}^{+} \mathrm{T}$ cells for E-cadherin ${ }^{+} \mathrm{CT}-26$ cells noted above could be suppressed by TGF- $\beta 1$ produced by $\mathrm{F} 4 / 80^{+} \mathrm{CD} 11 \mathrm{~b}^{\text {high }}$ Gr $1{ }^{\text {intermediate }}$ cells. As shown in Supplemental Figure 15, C and $\mathrm{D}$, we found that $M y d 88^{-/-} \mathrm{F} 4 / 80^{+} \mathrm{CD} 11 \mathrm{~b}^{\text {high }} \mathrm{Gr} 1^{\text {intermediate }}$ cells produced significantly reduced amounts of $T g f b 1$ in comparison with WT F4 $/ 80^{+} \mathrm{CD} 11 \mathrm{~b}^{\text {high }} \mathrm{Gr} 1^{\text {intermediate }}$ cells, and $M y d 88^{-1-} \mathrm{F} 4 / 80^{+}$ $\mathrm{CD} 11 \mathrm{~b}{ }^{\text {high }} \mathrm{Gr} 1^{\text {intermediate }}$ cells exerted almost no negative effect on $\mathrm{CD}^{+} \mathrm{T}$ cell cytotoxicity toward E-cadherin ${ }^{+} \mathrm{CT}-26$ cells (Supple-

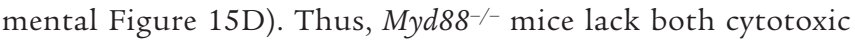
$\mathrm{CD} 103^{+} \mathrm{CD}^{+} \mathrm{T}$ cells that could mediate immunosurveillance of tumors as well as $\mathrm{F} 4 / 80^{+} \mathrm{CD} 11 \mathrm{~b}^{\text {high }} \mathrm{Gr} 1^{\text {intermediate }}$ cells that produce sufficient TGF- $\beta 1$ to inhibit the cytotoxic $\mathrm{CD}^{+} \mathrm{T}$ cells.

\section{Discussion}

Oxa-colitis is a murine model of human UC in that it bears a histologic resemblance to this disease and shares with it key immunological features $(3,5,20,21)$. Until now, the oxa-colitis model available for study has been characterized by an acute, short-lived inflammation that could not be used to analyze some of the features of UC typically associated with longstanding disease, such as colon carcinoma (6). Here, we describe a persistent form of oxacolitis induced in BALB/c mice by repeated intrarectal administration of oxazolone in ethanol that overcomes this problem and thus permits the use of this model to define specific features of the inflammatory milieu that favors tumor development. Chronic oxa-colitis begins as a severe inflammation and corresponding weight loss, which transforms into a chronic inflammation associated with a partial weight recovery. The inflammation is marked by the rapid increase in lamina propria cells producing IL-13 and the appearance of NKT cells, which are both immunologic features of acute oxa-colitis as well as UC. Evidence that the chronic inflammation is due to IL-13 production or NKT cells came from the fact that depletion of these elements leads to complete amelioration of the inflammation.

A major finding of this study is that chronic oxa-colitis supports epithelial tumor development induced by administration of AOM. Thus, when AOM-treated mice were examined 49 days after initia- 
tion of colitis, they exhibited tumor development, accompanied by reduced weight gain, and eventually intestinal obstruction by tumor growth. Importantly, tumor development was dependent on the presence of inflammation, since reversal of inflammation by IL-13 blockade or NKT cell depletion results in an almost tumor-free colon. These findings thus established that the Th2like inflammatory milieu of oxa-colitis is equally capable of supporting induced tumor development as the more usually studied Th1/Th17 inflammatory milieu of DSS-colitis.

In subsequent studies to investigate the cytokines and cells involved in the support of tumor development, we found first that the cytokine profile of mice with oxa-colitis and tumors was the same as that of mice with colitis without tumors with one critical exception: the former group exhibited increased lamina propria IL-6 production. Based on prior reports that macrophages support the metastatic behavior of both pulmonary and mammary tumor metastases, our initial presumption was that this cytokine production difference was due to the macrophage profile of tumor-bearing mice $(24,41)$. Indeed, we found that in parallel with the appearance of tumors, a particular subset of macrophages, F4/80 $\mathrm{CD} 11 \mathrm{~b}^{\text {high }} \mathrm{Gr} 1^{\text {low }}$ macrophages producing RNA characteristic of so-called M2 macrophages, were noted in the inflammatory infiltrate of mice with oxa-colitis administered AOM. Furthermore, we found that these macrophages produced high amounts of IL- 6 as well as another tumor-supporting factor, EGF. Since the onset of increased IL-6 production by lamina propria cells in mice with oxa-colitis treated with AOM was first seen on day 21 of colitis, the increase tracked with the appearance of the $\mathrm{F} 4 / 80^{+} \mathrm{CD} 11 \mathrm{~b}^{\text {high }} \mathrm{Gr} 1^{\text {low }}$ macrophages rather than the presence of activated T cells; it thus appears that these macrophages are a critical source of IL- 6 and other tumor-supporting factors in the lamina propria of tumor-bearing mice. In addition, concomitant $\mathrm{T}$ cell production of this cytokine may be dependent on the presence of these $\mathrm{F} 4 / 80^{+} \mathrm{CD} 11 \mathrm{~b}^{\text {high }} \mathrm{Gr} 1^{\text {low }}$ macrophages.

Previous studies have shown that macrophages that undergo alternative activation by exposure to Th2 cytokines (IL-4 and IL-13), so called M2 macrophages, promote tumor development by a variety of mechanisms $(22,23)$. It has been shown, for instance, that $\mathrm{F} 4 / 80^{+} \mathrm{CD} 11 \mathrm{~b}^{\text {high }} \mathrm{Gr} 1^{\text {low }}$ macrophages produce factors that support the metastatic growth of mammary tumors as a result of exposure to IL-4 or IL-13 produced by CD4 ${ }^{+} \mathrm{T}$ cells (24). NKT cells are one recognized source of IL-13 for such macrophage activation, and it is thus possible that IL-13-producing NKT cells generated during oxa-colitis act on macrophages drawn into sites of tumor development to induce their differentiation into tumor-supporting cells. This concept, while highly logical, cannot be easily verified, since inhibition of IL-13 abolishes the underlying inflammation supporting tumor induction. It derives indirect support, however, from the fact that mice with DSS-colitis that express colonic tumors as a result of exposure to AOM have inflammatory infiltrates that are devoid of $\mathrm{F} 4 / 80^{+} \mathrm{CD} 11 \mathrm{~b}^{\text {high }} \mathrm{Gr} 1^{\text {low }}$ macrophages and, concomitantly, produce only low amounts of IL-13.

Having shown that chronic oxa-colitis supports AOM-induced tumors, we conducted analyses of mice with Myd88 deficiency to identify cells and signaling pathways that underlie such support. These analyses were facilitated by the fact that while WT and $M y d 88^{-/-}$mice develop a chronic oxa-colitis that is equivalent both in mechanism and severity, only the former supports AOMinduced tumors. Thus, in the case of oxa-colitis, inflammationsupporting MyD88-dependent mechanisms could be separated from tumor-supporting MyD88-dependent mechanisms.
Several previous studies have provided evidence that MyD88 signaling is necessary for inflammation-associated tumor formation, albeit not under circumstances that clearly separate the effects of such signaling on inflammation from that on tumor growth (19, 42-45). Thus, it has been shown that $A \mathrm{Pc}^{\mathrm{MIN} /+} \mathrm{Myd88^{-/- }}$ mice exhibited reduced polyp formation and produced significantly less IL-6 when compared with $A p c^{M I N /+}$ WT mice (42). In addition, Abreu and coworkers showed that AOM-induced tumor formation in DSS-colitis depends on LPS stimulation of epithelial cells via TLR4 and subsequent epithelial cell production of various factors that support tumor growth (44). On the other hand, in a recent report, Salcedo et al. showed that Myd88 deficiency was associated with increased AOM-induced tumor development in DSS-colitis, which in this case was characterized by both adenomas and infiltrating adenocarcinomas (46). Analysis revealed that Myd88 deficiency led to decreased epithelial cell proliferation and increased apoptosis, which set the stage for the upregulation of genes associated with tissue renewal and repair; however, the latter did not compensate for the on-going epithelial cell injury, and a chronic epithelial cell disruption persisted accompanied by the upregulation of genes involved in colon tumorigenesis. Interestingly, a similar state occurred in $I l 18^{-/-}$and $I l 18 r 1^{-/-}$mice, strongly suggesting that a mainspring of the $M y d 88$ deficiency effect was reduced production of IL-18, a cytokine that is involved in maintenance of epithelial cell homeostasis. The increased tumor formation in DSS-colitis does not necessarily conflict with the decreased tumor formation in oxa-colitis reported here, since the nature of the colitis under study in the 2 reports is vastly different. In particular, the primary process driving DSS-colitis is DSS-induced epithelial cell injury so that defects in epithelial cell repair processes caused by Myd88 deficiency leads to increased tumor formation, which is probably independent of MyD88-induced tumor-supporting factors. In oxa-colitis, the tissue damage is not centered on the epithelial cells and the latter undergo self-repair in spite of Myd88 deficiency; nevertheless, AOM causes neoplastic transformation in the epithelial cells, which then require MyD88-dependent processes to manifest actual tumor formation.

In our analysis of the relation of MyD88 signaling to tumor formation, we noted that WT mice and Myd88 ${ }^{-1-}$ mice with oxa-colitis administered AOM are different in that lamina propria cells of WT mice but not $M y d 88^{-/-}$mice produce increased amounts of IL- 6 . In addition, we found that the lamina propria of WT mice contains a $\mathrm{F} 4 / 80^{+} \mathrm{CD} 11 \mathrm{~b}^{\text {high }} \mathrm{Gr} 1^{\text {low }}$ macrophage subset that produces high amounts of IL-6, whereas the Myd88-/$\mathrm{F} 4 / 80^{+} \mathrm{CD} 11 \mathrm{~b}^{\text {high }} \mathrm{Gr} 1^{\text {low }}$ macrophage subset does not. Evidence that this difference explains the lack of tumor development in

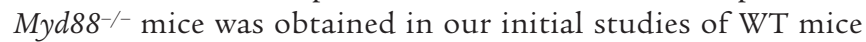
with oxa-colitis, in which we showed that treatment of mice with anti-IL-6 antibody prevented tumor development, yet had no effect on the underlying intestinal inflammation. In later studies, we confirmed the role of IL- 6 by showing that administration of IL- 6 or hyper-IL- 6 (i.e., IL- 6 bound to anti-IL-6R and therefore capable of trans-signaling epithelial cells) restored the ability of Myd88-1- mice to support AOM-induced tumor growth. These findings showing that deficient IL- 6 production underlies the inability of $\mathrm{Myd} 88^{-/-}$mice to facilitate tumor development are supported by 2 previous studies of AOM-induced tumor development in DSS-colitis. First, Becker et al. have shown that AOMinduced tumors in DSS-colitis require IL- 6 trans-signaling, i.e., signaling of tumor cells by an IL- 6 complex consisting of tumor 
cell-derived soluble IL-6R bound to lymphoid cell-derived IL-6 (14); such IL-6 trans-signaling was required to induce Stat 3 activation in tumor cells, since the latter express little if any membrane bound IL-6R. Second, Grivennikov et al. have shown that IL-6-deficient mice exhibit increased epithelial cell apoptosis and reduced AOM-induced tumors in DSS-colitis and that induction of Stat3 activation by IL-6 is critical to tumor cell growth (19). In addition to these studies of mice, studies of humans with gastrointestinal neoplasia provide evidence of an importance of IL-6 in the support of tumor growth: several clinical studies of colon neoplasms show that serum levels of IL- 6 are elevated in patients with colon cancer, and the amount of elevation correlates both with tumor size and the fact that IL- 6 supports the growth of human colon cancer cells in vitro (47-49).

The fact that IL- 6 is necessary for AOM-induced tumor development does not imply that this factor is sufficient for such development. We found that EGF is also produced by $\mathrm{F} 4 / 80^{+} \mathrm{CD} 11 \mathrm{~b}^{\text {high }} \mathrm{Gr} 1^{\text {low }}$ macrophages in mice exhibiting tumor formation and other tumor-supporting factors produced by these cells may also be identified in the future. These include some of the factors induced by TLR 4 signaling identified by Abreu and coworkers such as COX2 and certain chemoattractants $(13,44,50$, 51). However, since IL-6 alone was able to restore tumor formation in $M y d 88^{-1-}$ mice, it is likely that EGF and perhaps other tumorsupporting factors are "downstream" of IL-6. It should be noted that, inasmuch as IL-6 is clearly not the only tumor-supporting factor produced by $\mathrm{F} 4 / 80^{+} \mathrm{CD} 11 \mathrm{~b}^{\text {high }} \mathrm{Gr} 1^{\text {low }}$ cells, this indicates that exclusive IL- 6 production by these cells is not likely to be the only way in which these cells support tumor growth and that these cells play an important role even if it were shown that other lamina propria cells are also a source of IL- 6 during tumor development.

The fact that $\mathrm{F} 4 / 80^{+} \mathrm{CD} 11 \mathrm{~b}^{\text {high }} \mathrm{Gr} 1^{\text {low }}$ macrophage production of IL-6 is MyD88-dependent does not imply that signaling of TLR on macrophages is sufficient for IL-6 production. As alluded to above, work from Abreu et al. has shown that TLR4 signaling of epithelial cells is necessary for support of tumor formation in DSS-colitis, indicating that Myd88 deficiency can also operate at the level of epithelial cells (44). Indeed, this possibility gains important additional support from our BM reconstitution studies, which showed that while loss of MyD88-dependent signaling in hematopoietic cells (i.e., macrophages) has a quantitative, more important effect on tumor growth than loss of such signaling in nonhematopoietic cells (i.e., epithelial cells), the latter also had a significant effect on tumor growth, particularly with respect to tumor size. A mechanism of epithelial cell participation in support of tumor growth was recently suggested by Kim et al., who showed that tumor cells produce a factor (versican) that acts as an endogenous TLR stimulant of macrophages to induce IL- 6 production by the latter cells (41). Thus, the idea that best fits the data at hand is that TLR signaling must occur in both epithelial cells and macrophages to obtain the full set of factors that support tumor growth.

In conclusion, these studies linking IL-6-producing $\mathrm{F} 4 / 80^{+} \mathrm{CD} 11 \mathrm{~b}^{\text {high }} \mathrm{Gr} 1^{\text {low }}$ macrophages to the generation of intestinal tumors in a Th2-like experimental inflammation alert us to the possibility that a similar set of circumstances occurs in humans with longstanding UC who develop colonic cancer. It therefore will be valuable to determine whether patients with UC have increased numbers of such macrophages in the colonic mucosa and thus whether such macrophages can be a predictor of neoplastic development.

\section{Methods}

Mice. Female BALB/c mice (8 to 10 weeks old) were obtained from The Jackson Laboratory or from Charles River. BALB/c Myd88-/- animals were provided by S. Akira (Osaka University, Osaka, Japan). The animals were then maintained in the holding facilities of the National Institute of Allergy and Infectious Diseases and the University of Regensburg under specific pathogen-free conditions. Institutional review boards for the NIH and the University of Regensburg reviewed and approved the present study, which was performed under the guidelines of the Guide for the Care and Use of Laboratory Animals. To generate BM chimeras, 6-week-old WT or Myd88 $8^{--}$recipient mice were irradiated with $10 \mathrm{~Gy}$ from a $137 \mathrm{Cs}$ source, delivered in 2 doses of 5 Gy each, 3 hours apart. BM cells were isolated from 6- to 8-week-old WT or Myd88-/- donor mice by flushing the bone shafts of the femurs and tibias with RPMI, and $2.5 \times 10^{6} \mathrm{BM}$ cells thus obtained were intravenously injected into the recipient mice 3 hours after the last irradiation. WT mice were transplanted with $M y d 88^{-/-} \mathrm{BM}\left(\mathrm{Myd}^{-8^{--} \rightarrow \mathrm{WT}}\right)$,

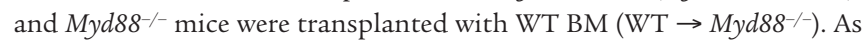
controls, WT mice were transplanted with WT BM, and Myd88-- mice were transplanted with $M y d 88^{-/-}$BM.

Induction of oxa-colitis. Mice were lightly anesthetized with isoflurane and then administered the haptenating agent oxazolone dissolved in ethanol intrarectally via a 3.5 French (F) catheter equipped with a $1-\mathrm{ml}$ syringe; the catheter was advanced into the rectum until the tip was $4-\mathrm{cm}$ proximal to the anal verge, at which time the haptenating agent was administered in a total volume of $150 \mu \mathrm{l}$. For chronic oxa-colitis, $2 \mathrm{mg}$ oxazolone in $47.5 \%$ ethanol was administered every 7 days. To induce tumor development, mice received an initial i.p. injection of AOM $10 \mathrm{mg} / \mathrm{kg}$ shortly before the first oxazolone administration.

Construction of plasmids. For the $p C I-s I L-13 R \alpha_{2}-F c$ plasmid, first, $I L-13 R \alpha_{2}$ cDNA was inserted into the pCI-Mammalian Expression Vector (Promega). In the second step, the cDNA encoding for the Fc part of a human IgG was inserted after the $I L-13 R \alpha_{2}$ cDNA to connect both inserts, resulting in a soluble form of the IL-13R $\alpha_{2}$. For the pCIneo-E-cadherin plasmid, E-cadherin was cloned from CMT93 cells and then inserted into the PCIneo-Mammalian Expression Vector (Promega).

Blockade of IL-13, IL-6, EGF, CD1, TGF- $\beta 1$, and CD103. IL-13 blockade was achieved with a plasmid (100 $\mu \mathrm{g}$ in $20 \mu \mathrm{lBS} /$ mouse) encoding a soluble IL-13R $\alpha_{2}$-Fc fusion protein ( $\left.p C I-s I L-13 R \alpha_{2}-F c\right)$ or a control plasmid (pCI empty vector) by intranasal instillation every other day, starting on day 20 , after initiation of chronic oxa-colitis. Verification of transfection of the $s I L-13 R \alpha_{2}-F c$ plasmid was demonstrated by the expression of the human Ig-Fc (a component of the plasmid product) in colonic tissue extracts (data not shown). IL-6 blockade was accomplished by administration of neutralizing goat IgG anti-IL- 6 antibody (R\&D Systems) (500 $\mu \mathrm{g}$ once weekly, starting on day 20, after initiation of chronic oxa-colitis). EGF blockade was accomplished by administration of neutralizing goat IgG anti-EGF antibody (R\&D Systems) $(500 \mu \mathrm{g}$ once weekly, starting on day 20, after initiation of chronic oxa-colitis). CD1 blockade was accomplished by administration of neutralizing rat IgG anti-CD1 antibody (clone 20H2) (ATCC) (500 $\mu$ g once weekly, starting on day 20, after initiation of chronic oxa-colitis). Antibody treatment in vivo was performed once weekly, starting on day 20 , after initiation of chronic oxa-colitis. For in vitro blockade of TGF- $\beta 1$, a neutralizing rat IgG anti-TGF- $\beta 1$ antibody was used. A rat IgG (Invitrogen) served as isotype control antibody. For in vitro blockade of CD103, a neutralizing rat IgG anti-CD103 antibody (R\&D Systems) was used. Respective IgG (Invitrogen) served as isotype control antibody.

Hyper-IL-6. To induce IL-6 functions in vivo, hyper-IL-6 (IL-6/sIL-6R fusion protein) mice were injected i.p. with $2 \mu \mathrm{g}$ hyper-IL-6 in $100 \mu \mathrm{l} 1 \mathrm{X}$ PBS every week, starting on day $20(14,34-36,52)$. 
Cell isolation and culture. Colonic LPMCs were isolated from colonic tissues as previously described and then cultured for 48 hours in the presence of various stimulants (31). The capacity of cultured LPMCs to secrete IL-13 and IL- 6 was determined by stimulation with plate-bound anti-CD3 antibody $(10 \mu \mathrm{g} / \mathrm{ml})$ and soluble anti-CD28 antibody $(1 \mu \mathrm{g} / \mathrm{ml})$ (BD Biosciences) or S. aureus Cowan I (1:10,000 dilution of Pansorbin) (EMD Biosciences) and IFN- $\gamma(1,000 \mathrm{U} / \mathrm{ml})(\mathrm{R} \& \mathrm{D}$ Systems). Cytokine concentrations were measured by ELISA according to manufacturer's instructions. ELISA Kits for IL- 6 were purchased from BD Biosciences, and those for IL-13 were purchased from R\&D Systems.

Immunohistochemistry. Formalin-fixed and paraffin-embedded samples were deparaffined, rehydrated, and pretreated with $3 \%$ hydrogen peroxidase in PBS buffer. Sections were incubated with anti- $\beta$-catenin antibody or anti-E-cadherin antibody (Cell Signaling Technology) for 1 hour at room temperature. After incubation with biotin-conjugated secondary antibody and streptavidin-HRP, positive signals were visualized by a DAB Kit (BD Pharmingen). Paraffin-embedded colon sections were also cut and then stained with H\&E. For calculation of inflammation indices in treated and control group of mice, the $\mathrm{H} \& \mathrm{E}$ sections were read by investigators blinded to the experimental protocol and evaluated according to formerly published scoring systems for TNBS-colitis and oxa-colitis $(53,54)$. Measurements of tumor nodules refer to diameter and were made using a digitally obtained image of the whole tissue section. Evaluation was performed using the Mirax Viewer software (Carl Zeiss AG).

CTL assays. CTL assays were performed using isolated $\mathrm{CD}^{+}$cells obtained from single-cell suspensions of from tumor-bearing colon tissue from mice with chronic oxa-colitis with AOM-induced tumors. Isolated $\mathrm{CD}^{+}$cells $\left(2 \times 10^{5}\right.$ cells $)$ were coincubated in vitro with CT- 26 cells or E-cadherin-transfected CT- 26 cells $\left(5 \times 10^{4}\right.$ cells $)$ and treated with mitomycin C. For coculture experiments, $\mathrm{F} 4 / 80^{+} \mathrm{CD} 11 \mathrm{~b}^{\text {high }} \mathrm{Gr} 1^{\text {low }}$ or $\mathrm{F} 4 / 80^{+} \mathrm{CD} 11 \mathrm{~b}^{\text {high }} \mathrm{Gr} 1^{\text {intermediate }}$ cells $\left(2 \times 10^{4}\right.$ cells $)$ were added to the CTL assay. After 24 hours, cytolytic activity against CT-26 cells or E-cadherintransfected CT-26 cells was determined by the CellTiter-Glo Luminescent Cell Viability Assay (Promega).

Flow cytometry. Colonic LPMCs were isolated and subjected to flow cytometry. For staining, cells were treated with monoclonal antibodies to mouse anti-CD4, anti-CD8, anti-CD103, CD11b, anti-F4/80 (all from eBiosciences), anti-Gr1 (Miltenyi Biotec), and with CD1d tetramer (Proimmune), respectively. Nonspecific binding of antibodies was blocked by preincubation with Fcy block.

Real-time PCR. Aliquots of isolated cells were stored in RNAlater solution (Ambion) and then subjected to RNA extraction using the RNeasy Tissue Kit (Qiagen). Occasionally, the MessageAmp aRNA Amplification Kit (Ambion) was used to obtain sufficient RNA template. A total of $100 \mathrm{ng}$ template RNA was reverse transcribed with the SuperScript III RT-PCR Kit (Invitrogen). Primer sequences were as follows: Il6, CCGGAGAGGAGACTTCACAG and TTCTGCAAGTGCATCATCGT; Egf, CCCAGGCAACGTATCAAAGT and GGTCATACCCAGGAAAGCAA; Tg $f b 1$, TGCGCTTGCAGAGATTAAAA and CTGCCGTACAACTCCAGTGA; and Actb, AGCCATGTACGTAGCCATCC and CTCTCAGCTGTGGTGGTGAA.

Statistics. For calculation of differences in body weight, a multivariate analysis (if significant) followed by a Mann-Whitney test for each time point was used. For calculation of differences in histology score, a KruskalWallace test with Dunn's multiple comparison test was used. For calculation of differences in the number of tumor nodules and cytokine levels, a 2-way ANOVA test with Bonferroni post-test was used. Statistics were computed by GraphPad Prism 4 to evaluate the significance of the differences. A value of $P<0.05$ was considered statistically significant.

\section{Acknowledgments}

This project was supported by grant Fi1526/1-1 from the Deutsche Forschungsgemeinschaft. The authors gratefully acknowledge this support. The authors also thank Jörg Marienhagen and Laura Cojocaru for the help with statistical calculations.

Received for publication August 3, 2010, and accepted in revised form March 11, 2011.

Address correspondence to: Stefan Fichtner-Feigl, Department of Surgery, University of Regensburg, Franz-Josef-Strauss-Allee 11, 93053 Regensburg, Germany. Phone: 49.941.944.6868; Fax: 49.941.944.6802; E-mail: stefan.fichtner@klinik.uni-regensburg.de.
1. Podolsky DK. Inflammatory bowel disease. $N$ Engl JMed. 2002;347(6):417-429.

2. Bouma G, Strober W. The immunological and genetic basis of inflammatory bowel disease. Nat Rev Immunol. 2003;3(7):521-533.

3. Fuss IJ, et al. Nonclassical CD1d-restricted NK $\mathrm{T}$ cells that produce IL-13 characterize an atypical Th2 response in ulcerative colitis. J Clin Invest. 2004;113(10):1490-1497.

4. Strober W, Fuss I, Mannon P. The fundamental basis of inflammatory bowel disease. J Clin Invest. 2007;117(3):514-521.

5. Heller F, et al. Interleukin-13 is the key effector Th2 cytokine in ulcerative colitis that affects epithelial tight junctions, apoptosis, and cell restitution. Gastroenterology. 2005;129(2):550-564.

6. Lakatos PL, Lakatos L. Risk for colorectal cancer in ulcerative colitis: changes, causes and management strategies. World J Gastroenterol. 2008;14(25):3937-3947.

7. Eaden JA, Abrams KR, Mayberry JF. The risk of colorectal cancer in ulcerative colitis: a meta-analysis. Gut. 2001;48(4):526-535.

8. Eaden JA, Mayberry JF. Colorectal cancer complicating ulcerative colitis: a review. Am J Gastroenterol. 2000;95(10):2710-2719.

9. Clevers $H$. At the crossroads of inflammation and cancer. Cell. 2004;118(6):671-674.

10. Waldner MJ, Neurath MF. Colitis-associated cancer: the role of $\mathrm{T}$ cells in tumor development. Semin
Immunopathol. 2009;31(2):249-256.

11. Waldner M, Schimanski CC, Neurath MF. Colon cancer and the immune system: the role of tumor invading T cells. World J Gastroenterol. 2006;12(45):7233-7238.

12. Lin WW, Karin M. A cytokine-mediated link between innate immunity, inflammation, and cancer. J Clin Invest. 2007;117(5):1175-1183.

13. Fukata M, Abreu MT. Pathogen recognition receptors, cancer and inflammation in the gut. Curr Opin Pharmacol. 2009;9(6):680-687.

14. Becker C, et al. TGF-beta suppresses tumor progression in colon cancer by inhibition of IL- 6 transsignaling. Immunity. 2004;21(4):491-501.

15. Greten FR, et al. IKKbeta links inflammation and tumorigenesis in a mouse model of colitis-associated cancer. Cell. 2004;118(3):285-296.

16. Popivanova BK, et al. Blocking TNF-alpha in mice reduces colorectal carcinogenesis associated with chronic colitis. J Clin Invest. 2008;118(2):560-570.

17. Zhang J, et al. Impaired regulation of NF-kappaB and increased susceptibility to colitis-associated tumorigenesis in CYLD-deficient mice. J Clin Invest. 2006;116(11):3042-3049.

18. Bollrath J, et al. gp130-mediated Stat 3 activation in enterocytes regulates cell survival and cell-cycle progression during colitis-associated tumorigenesis. Cancer Cell. 2009; 15(2):91-102.

19. Grivennikov S, et al. IL-6 and Stat3 are required for survival of intestinal epithelial cells and devel- opment of colitis-associated cancer. Cancer Cell. 2009;15(2):103-113.

20. Fichtner-Feigl S, Fuss IJ, Preiss JC, Strober W, Kitani A. Treatment of murine Th1- and Th2-mediated inflammatory bowel disease with NF-kappaB decoy oligonucleotides. JClin Invest. 2005;115(11):3057-3071.

21. Heller F, Fuss IJ, Nieuwenhuis EE, Blumberg RS, Strober W. Oxazolone colitis, a Th2 colitis model resembling ulcerative colitis, is mediated by IL-13-producing NK-T cells. Immunity. 2002;17(5):629-638.

22. Sinha P, Clements VK, Ostrand-Rosenberg S. Interleukin-13-regulated M2 macrophages in combination with myeloid suppressor cells block immune surveillance against metastasis. Cancer Res. 2005;65(24):11743-11751.

23. Gordon S, Martinez FO. Alternative activation of macrophages: mechanism and functions. Immunity. 2010;32(5):593-604.

24. DeNardo DG, et al. CD4(+) T cells regulate pulmonary metastasis of mammary carcinomas by enhancing protumor properties of macrophages. Cancer Cell. 2009;16(2):91-102.

25. Pardoll D. Metastasis-promoting immunity: when T cells turn to the dark side. Cancer Cell. 2009; 16(2):81-82.

26. Mantovani A, Locati M. Orchestration of macrophage polarization. Blood. 2009;114(15):3135-3136.

27. Mantovani A, Sica A, Allavena P, Garlanda C, Locati M. Tumor-associated macrophages and the related myeloid-derived suppressor cells as a paradigm of the 
diversity of macrophage activation. Hum Immunol. 2009;70(5):325-330

28. Fichtner-Feigl S, et al. Induction of IL-13 triggers TGF-beta1-dependent tissue fibrosis in chronic 2,4,6-trinitrobenzene sulfonic acid colitis.J Immunol. 2007;178(9):5859-5870.

29. Fichtner-Feigl S, Young CA, Kitani A, Geissler EK, Schlitt HJ, Strober W. IL-13 signaling via IL-13R alpha2 induces major downstream fibrogenic factors mediating fibrosis in chronic TNBS colitis. Gastroenterology. 2008;135(6):2003-2013.e7.

30. Lawrance IC, et al. A murine model of chronic inflammation-induced intestinal fibrosis downregulated by antisense NF-kappa B. Gastroenterology. 2003;125(6):1750-1761.

31. Boirivant M, Fuss IJ, Chu A, Strober W. Oxazolone colitis: A murine model of T helper cell type 2 colitis treatable with antibodies to interleukin 4.J Exp Med. 1998;188(10):1929-1939.

32. Mudter J, et al. The transcription factor IFN regulatory factor- 4 controls experimental colitis in mice via T cell-derived IL-6. J Clin Invest. 2008;118(7):2415-2426.

33. Gavert N, Ben-Ze'ev A. beta-Catenin signaling in biological control and cancer. J Cell Biochem. 2007;102(4):820-828

34. Dominitzki S, et al. Cutting edge: trans-signaling via the soluble IL-6R abrogates the induction of FoxP3 in naive CD4+CD25 T cells. J Immunol. 2007;179(4):2041-2045.

35. Atreya R, Neurath MF. Signaling molecules: the pathogenic role of the IL-6/STAT-3 trans signaling pathway in intestinal inflammation and in colonic cancer. Curr Drug Targets. 2008;9(5):369-374.
36. Weigmann B, et al. The transcription factor NFATc2 controls IL-6-dependent $\mathrm{T}$ cell activation in experimental colitis. J Exp Med. 2008;205(9):2099-2110.

37. Berzofsky JA, Terabe $M$. The contrasting roles of NKT cells in tumor immunity. Curr Mol Med. 2009;9(6):667-672.

38. Terabe M, Berzofsky JA. The role of NKT cells in tumor immunity. Adv Cancer Res. 2008;101:277-348.

39. Fichtner-Feigl S, et al. Restoration of tumor immunosurveillance via targeting of interleukin-13 receptor-alpha 2. Cancer Res. 2008;68(9):3467-3475.

40. Franciszkiewicz K, et al. Intratumoral induction of CD103 triggers tumor-specific CTL function and CCR5-dependent T-cell retention. Cancer Res. 2009;69(15):6249-6255.

41. Kim S, et al. Carcinoma-produced factors activate myeloid cells through TLR2 to stimulate metastasis. Nature. 2009;457(7225):102-106.

42. Rakoff-Nahoum S, Medzhitov R. Regulation of spontaneous intestinal tumorigenesis through the adaptor protein MyD88. Science. 2007; 317(5834):124-127.

43. Uronis JM, Muhlbauer M, Herfarth HH, Rubinas TC, Jones GS, Jobin C. Modulation of the intestinal microbiota alters colitis-associated colorectal cancer susceptibility. PLoS One. 2009;4(6):e6026.

44. Fukata M, et al. Toll-like receptor-4 promotes the development of colitis-associated colorectal tumors. Gastroenterology. 2007;133(6):1869-1881.

45. Matsumoto S, et al. Essential roles of IL- 6 transsignaling in colonic epithelial cells, induced by the IL-6/soluble-IL-6 receptor derived from lamina propria macrophages, on the development of colitis-associated premalignant cancer in a murine model. J Immunol. 2010;184(3):1543-1551.

46. Salcedo R, et al. MyD88-mediated signaling prevents development of adenocarcinomas of the colon: role of interleukin 18. J Exp Med. 2010; 207(8):1625-1636.

47. Dann SM, et al. IL-6-dependent mucosal protection prevents establishment of a microbial niche for attaching/effacing lesion-forming enteric bacterial pathogens. J Immunol. 2008;180(10):6816-6826.

48. Tebbutt NC, et al. Reciprocal regulation of gastrointestinal homeostasis by SHP2 and STAT-mediated trefoil gene activation in gp130 mutant mice. Nat Med. 2002;8(10):1089-1097.

49. Heikkila K, Ebrahim S, Lawlor DA. Systematic review of the association between circulating interleukin-6 (IL-6) and cancer. Eur J Cancer. 2008; 44(7):937-945

50. Fukata M, Abreu MT. Role of Toll-like receptors in gastrointestinal malignancies. Oncogene. 2008; 27(2):234-243.

51. Fukata M, Abreu MT. TLR4 signalling in the intestine in health and disease. Biochem Soc Trans. 2007;35(pt 6):1473-1478.

52. Fischer M, et al. I. A bioactive designer cytokine for human hematopoietic progenitor cell expansion. Nat Biotechnol. 1997;15(2):142-145.

53. Boirivant M, Strober W, Fuss IJ. Regulatory cells induced by feeding TNP-haptenated colonic protein cross-protect mice from colitis induced by an unrelated hapten. Inflamm Bowel Dis. 2005;11(1):48-55.

54. Fuss IJ, Marth T, Neurath MF, Pearlstein GR, Jain A Strober W. Anti-interleukin 12 treatment regulates apoptosis of Th1 $\mathrm{T}$ cells in experimental colitis in mice. Gastroenterology. 1999;117(5):1078-1088. 